Portland State University

PDXScholar

$12-15-2014$

\title{
The Impact of Documentation Status on the Educational Attainment Experiences of Undocumented Hispanic/Latino Students
}

Brittanie Alexandria Roberts

Portland State University

Follow this and additional works at: https://pdxscholar.library.pdx.edu/open_access_etds

Part of the Educational Sociology Commons, Higher Education Commons, and the Race and Ethnicity Commons

Let us know how access to this document benefits you.

\section{Recommended Citation}

Roberts, Brittanie Alexandria, "The Impact of Documentation Status on the Educational Attainment Experiences of Undocumented Hispanic/Latino Students" (2014). Dissertations and Theses. Paper 2083. https://doi.org/10.15760/etd.2081

This Thesis is brought to you for free and open access. It has been accepted for inclusion in Dissertations and Theses by an authorized administrator of PDXScholar. Please contact us if we can make this document more accessible: pdxscholar@pdx.edu. 
The Impact of Documentation Status on the Educational Attainment Experiences of Undocumented Hispanic/Latino Students

by

Brittanie Alexandria Roberts

A thesis submitted in partial fulfillment of the requirements for the degree of

Master of Science

in Sociology

Thesis Committee:

Margaret Everett, Chair Alex Stepick

Elena Avilés

Portland State University 2014 
(C) 2014 Brittanie Alexandria Roberts 


\begin{abstract}
The issue of undocumented immigration has recently taken center-stage in the media and national politics in the United States. A large population of undocumented youth grows up with legal access to public education through high school, following the Supreme Court decision of Plyler vs. Doe, but faces legal and economic barriers to postsecondary education. Following high school, undocumented Hispanic/Latino youth legal protections end, greatly limiting chances for upward mobility through traditional postsecondary education pipelines. In some cases, knowledge of future barriers to postsecondary education leads to a decline in educational motivation.
\end{abstract}

The current political atmosphere makes this study a bit of a moving target as the Obama administration recently passed a reprieve. This reprieve, known as Deferred Action for Childhood Arrivals Process (DACA) does not confer any legal status or open any future path to citizenship. It does, however, grant eligible applicants a work permit, and the opportunity to travel, work, and attend school with a sense of security.

The purpose of this thesis is to better understand the perceptions and understandings of undocumented Hispanic/Latino youth and their pursuits of higher education in. It is primarily concerned with the educational issues and opportunities facing these students. This research explores the impact of Hispanic/Latino students' perceptions of legal status barriers on their educational attainment experiences. The different opportunities and obstacles present in access to post-secondary education for undocumented Hispanic/Latino students residing in the United States are examined. This 
study focuses on the time period just after high school graduation, a critical stage in these students' lives, when undocumented status is particularly consequential.

Knowledge about students' perception of their educational progress sheds light on their educational attainment experiences; it illuminates important factors associated with their individual educational experiences. Interactions with teachers, school authorities, their parents, siblings, peers, and other authority figures could be described in connecting personal interpretations and emotional responses to specific events in their lives that they feel helped or hindered their educational progress. Knowing how undocumented Hispanic/Latino youth identify and understand the factors that facilitate or impede their navigation of post-secondary education, will further inform educators and researchers alike.

This study offers the possibility of identifying additional factors for educators, researchers, and our communities that hinder or facilitate the educational navigation and success of undocumented students. This type of research is significant as this marginalized population lives and works within the American society; the successes and struggles of these students impacts the United States as a whole. Moreover, these students possess amazing potential; we need to better understand and serve this population in order to both improve their life experiences, and to benefit from their input and abilities. 


\section{DEDICATION}

To

all of my family

in recognition of their unlimited love and patience through this long process

And

to my mentees,

whose experiences as undocumented Hispanic/Latino students

inspired this project 


\section{ACKNOWLEDGEMENTS}

To all of those who made this possible:

First and foremost, I need to express my gratitude for the unconditional love and support my family has provided me during the prolonged period of time it took me to complete this work. Your continued patience and many sacrifices have not gone unnoticed. This thesis would not have successfully made it to completion without the continued mentorship and support of Professor Margaret Everett. Margaret's confidence in my ability to complete my work, and her consistent presence provided me the confidence I needed to press on. Professor Everett's insight and great experience allowed me to learn on the go throughout this process. I am ever grateful for her steadfastness and willingness to stay with me.

I also wish to acknowledge Professor Stepick, and Dr. Munoz, whose expertise contributed valuable insight into my thesis. I am especially grateful for their support and willingness to participate as part of my committee when my thesis became drawn out and the ending unknown. I appreciate their cooperation, considering their larger work schedules and various other commitments. Thank you.

Additionally, Professor Aviles deserves special thanks for her willingness to participate on such short notice. After the loss of one committee member, I required a replacement only weeks before my defense. Professor Aviles bravely agreed to serve on my 
committee, and her doing so allowed me to defend and graduate in a timely and costeffective manner.

My cohort at Portland State University deserves extraordinary thanks on many levels. Their friendship, commiseration, collaboration and united show of strength illustrated how fortunate I was to have such intelligent and caring people as my peers. I am especially grateful to their communications and service after the trying birth of my son. To my cohort -Daniel Standridge, Erica Jean, Miro Paljevic, Kym Jade, Elisabeth Wilder, Aaron Bach, Patrick Smith, Jeff Shelton, Christy Richardson, Marco Aguirre, and Jerry Loveless, thank you. I wish I could have graduated with all of you, but having you as my graduate cohort was blessing enough. Gideon and I cannot express how comforting it was to have your support.

At Portland Community College, I acknowledge Brenda Ivelisse Maldonado as my mentor and inspiration. If it had not been for Brenda's "recruitment" of me to Oregon Leadership Institute all those years ago, I would never have met my mentees and this project likely would have never taken place. It has been my goal to follow in Brenda's footsteps and serve students and communities to the extent of my abilities. Brenda has also been kind enough to offer support and insight when I have been unsure of myself and my ability to carry out this research competently. Brenda Ivelisse Maldonado, I do not think you know how influential you have been in my life, but you should know I am extremely grateful. 
To all of those who gave their time for this research. The sixteen young men and women who volunteered to meet with me and share their life experiences are my heroes. I am grateful for your trust, your participation, and I am in awe of your strength and resilience. I wish I could list your names as requested, but you all know who you are. I hope that by sharing this research I can play some small part in galvanizing progress towards reforming immigration and creating a pathway for citizenship that you may benefit from this work as much as I have. Thank you.

I cannot forget to express my appreciation to my community. For every hardship I encountered along the way, there was someone to smooth out the bumps, and help simplify my many concerns. Heidi Rice, I would not trust anyone outside of my family but you to take care of my son. That you willingly watch my son for a price that I can afford as a student and a mother (which is a steal) puts me forever in your debt. I hope someday I can find a way to return this enormous favor. The Stewards have always been a huge support for me and my family, and I am grateful for their steady presence and involvement in our lives. To my neighbors who have supported me in a multitude of ways, and for the many people of Vernonia, Oregon who did not ostracize me when it became clear that I would not graduate on time. If anything, you were too forgiving, allowing me to be lulled into a state of suspended production. Thank you. You are all what I needed during these last few years. I hope to be able to better serve you all in the future now that this part of my life is coming to an end. 
Lastly, I want to recognize my mentees. You are the only reason this research came into being. If you had not trusted me as your mentor all those years ago, I would never have had the motivation or inspiration to pursue this degree. My life would have been very different had I never met you. I wish I could list your names so everyone could know who you are, but I will have to be content with knowing that you know who you are. Thank you both. You have been there for me as much as I have tried to be there for you, and I am grateful. 


\section{TABLE OF CONTENTS}

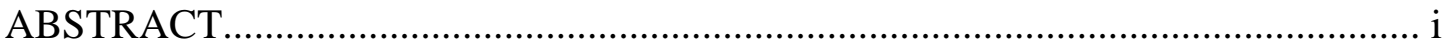

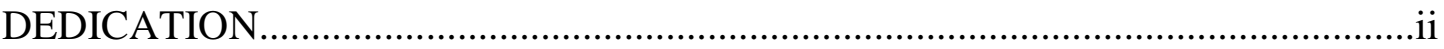

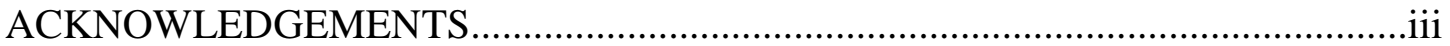

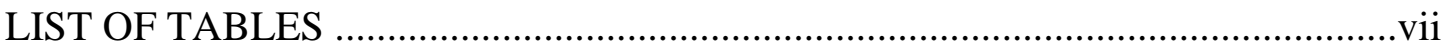

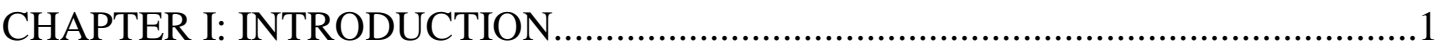

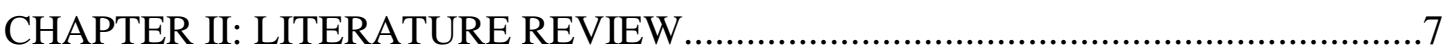

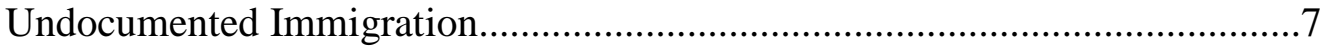

Target Immigration Policies.............................................................................

Undocumented Youth: The 1.5 Generation......................................................25

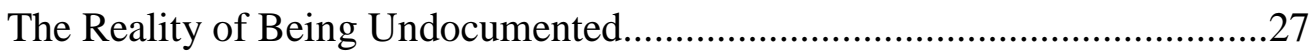

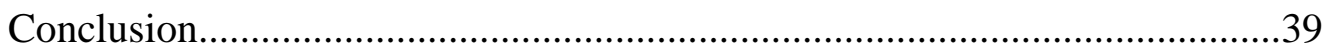

CHAPTER III: THEORETICAL FRAMEWORK...................................................41

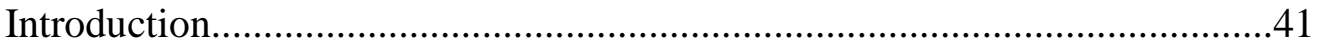

Classic Assimilation Theory..............................................................................41

Racial/Ethnic Disadvantage Assimilation Theory ...........................42

Segmented Assimilation Theory.........................................43

Conclusion .............................................................

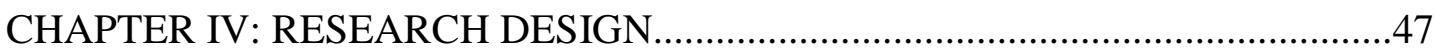

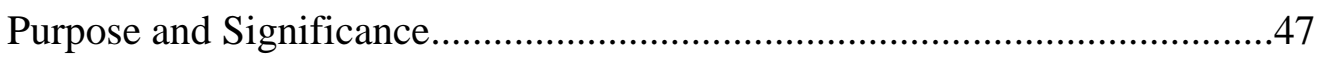

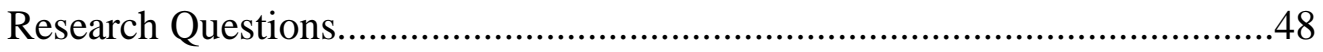

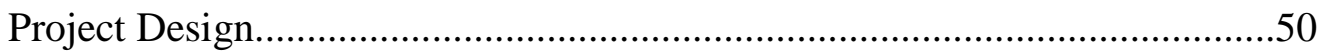

Participants and Sampling Frame 


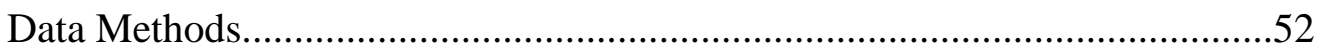

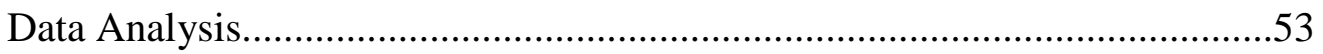

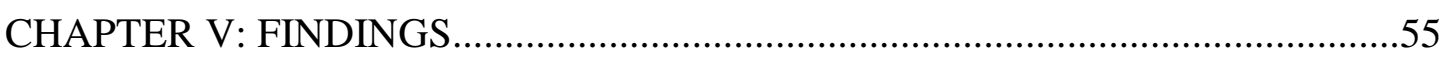

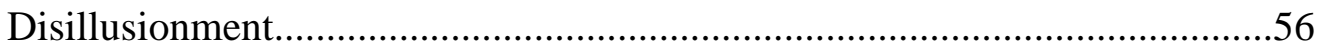

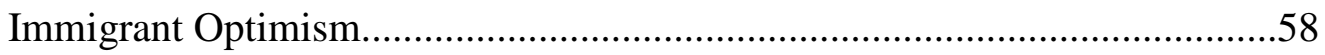

Limited Opportunities........................................................................62

Importance of Social Support.............................................................66

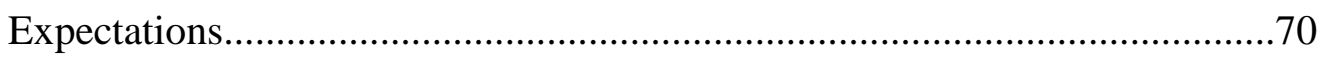

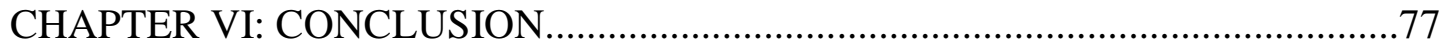

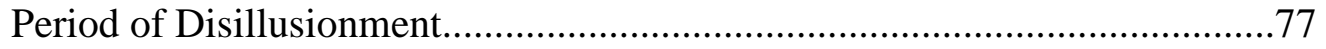

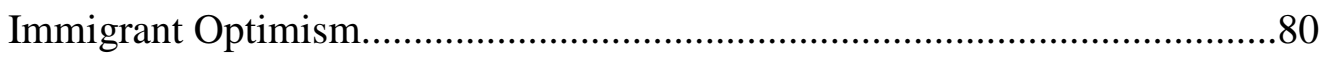

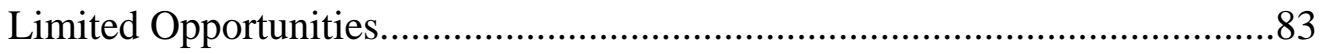

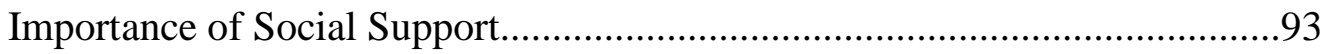

Review of Research Questions.........................................................96

Barriers to Educational Attainment................................................102

Contributions................................................................................ 110

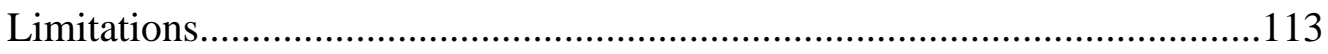

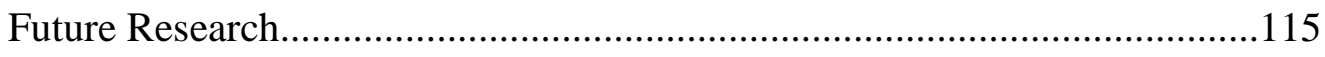

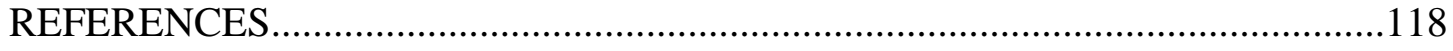

APPENDIX: Informed Consent Cover Letter......................................................125 


\section{LIST OF TABLES}

Table 1: Gang Presence and Demographic Comparison between Border States and

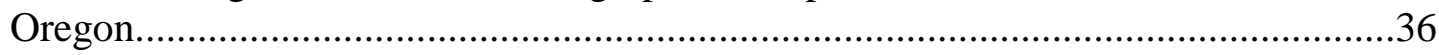

Table 2: Participant's Basic Information................................................................51

Table 3: Parent's Education.....................................................................................

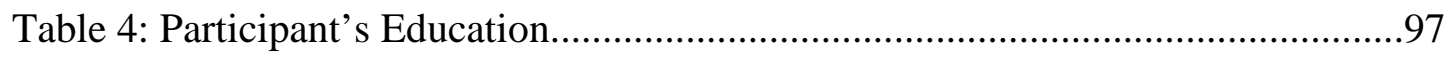




\section{Chapter I: Introduction}

Juanes ${ }^{1}$ was a senior in high school with top grades and a history of student leadership participation. His education had taken place entirely in Portland public schools where he excelled academically. Juanes's goals were to be accepted into a four-year university on the East Coast and earn a degree in political science. Juanes was devastated when he discovered that despite his 4.0 GPA and extracurricular activities as a student he would not be able to attend any of the four-year universities he had worked towards; because he was not a documented citizen. Juanes became disheartened and stopped applying himself in his last quarter of school. He also confessed to considering suicide as an alternative to what he saw as "a dead-end future" (Roberts 2010).

The issue of undocumented immigration has recently taken center-stage in the media and national politics in the United States. A substantial population of undocumented youth is growing up with legal access to public education, but is facing legal and economic barriers to post-secondary education (Abrego 2006: 212). After high school, undocumented Hispanic/Latino ${ }^{2}$ youth legal protections end, greatly limiting chances for upward mobility through education. The legal and social contradictions associated with undocumented status limit these youths' chances for upward mobility

\footnotetext{
${ }^{1}$ All names have been changed; pseudonyms were chosen and used to identify undocumented Hispanic/Latino youth in order to protect identity and privacy.

${ }^{2}$ Due to conflict over the definitions and applicability of the terms Hispanic and Latino, you will notice that this thesis uses the two terms together, Hispanic/Latino, based on alphabetical order. With this term, people that connect with both terms are recognized, and people who identify with just one of the two terms are included. These two terms may or may not mean the same thing to everyone, and by using the two terms together, I hope to use a term that is more inclusive and accurate.
} 
through traditional means (Abrego 2006: 212). In some cases, knowledge of future barriers to post-secondary education leads to a decline in educational motivation. Based on in-depth interviews, this study examines the experiences of undocumented Hispanic/Latino youth in the Portland metro area. This research is important as it addresses the educational issues and opportunities facing these students.

The current political atmosphere makes this study a bit of a moving target. The Obama administration recently announced that "certain people who came to the United States as children and meet several key guidelines may request consideration of deferred action for a period of two years... and would then be eligible for work authorization" (Immigration Equality 2012). This reprieve, known as Deferred Action for Childhood Arrivals Process (DACA) does not confer any legal status or open any future path to citizenship. However, in the wake of the largest deportation scale seen in decades, this reprieve is considered a gateway for better things to come. Many hope that Obama's second administration will focus on the passage of the DREAM Act, and confer legal status to young immigrants as long as they meet key guidelines.

I have been working with the Hispanic/Latino population for the past three years. It has been a rewarding process working with students, instructors, and group activists to address the many issues that face the Hispanic/Latino population in Oregon, as well as the nation. My inspiration for this research came from my volunteer work with this population. I was a mentor for the Oregon Leadership Institute (OLI) program at Portland Community College, Rock Creek Campus. I was responsible for three Hispanic/Latino 
boys in high school. At a Saturday session for the OLI group, we as mentors introduced a "learning exercise" called "The Line Game".

Adapted from the film Freedom Writers, this game has students step forward and put their toes on a line made by the instructor for every question that applies to them. It works by starting innocently enough; if your favorite color is green, step forward, if you play (soccer, football, basketball, etc.), step forward, or if you have parents, who are divorced, step forward. Non-invasive questions begin to build to more serious and significant matters, such as, if you or someone you know has had a child before the age of 17 , step forward, if you or someone you know is in a gang, step forward, and so on. After the game, mentors were released to debrief with their mentees.

My mentees and I spent a couple of minutes discussing the more invasive questions before I attempted to lighten the discussion with a teasing jest at two of my mentees who were graduating seniors. It was meant to be a joke, coming from my observation that when the mentor conducting the exercise asked everyone with a driver's license to step forward, two of my mentees remained behind. After asking them why they were "not cool enough to have a license yet," my mentees looked at each other and then told me they could not obtain a driver's license because they were undocumented. I did my best to act natural, but I was shocked.

I had only recently learned about students who grew up in the United States without documentation and how this affected their goals for the future, but I had never known a student to be in this particular position before. And now I knew two of them, and I was supposed to mentor them. It was my responsibility to impart knowledge on 
how to apply to college, how to fill out FAFSA, and how to apply for scholarships, and I was beginning to feel overwhelmed. I did not know enough about the legal and educational barriers these students faced every day, let alone the barriers they would face when they graduated.

I realized then that I wanted my mentees to have the same educational opportunities as documented and U.S. citizen students. I wanted my mentees to have the same rights and privileges awarded to documented students. At the time, I did not know how I was going to accomplish this, but it was a start. It was at the end of my undergraduate studies that I was able to more specifically focus my interest. I wanted to know the reality of what these students faced when they graduated high school, and more importantly, I wanted to know what happened when they were denied access to postsecondary education. What did that do to their identity? How did this affect their goals? What did they feel were their options if this door closed?

I began to formulate a project, a study to address these issues. Through interaction with instructors and mentors I was able to better define my intent, my design, and my expected results. I found related literature and previously conducted studies from different states (Abrego 2006; Gonzales 2009; Gonzales 2008; Perez et al. 2009). I talked to my mentees, their friends, and friends I made throughout my undergraduate who were also part of this undocumented student population. Based on the information and experiences shared, this study is significant because of the ways it contests the popular criminalized image of undocumented Hispanic/Latino immigrants. The value of this 
study is in its purpose of giving voice to a population of people who's emotional, educational, and physical needs are regularly violated.

Chapter two reviews the literature on undocumented immigrants, which includes a discussion on immigrants in general, followed with a section on the 1.5 generation specifically. This is done to identify the differences between "generations" of immigrants, and how documentation status affects immigrants' lives. This chapter also highlights historical immigration policies which altered the process of immigration for Hispanic/Latino immigrants in the United States, and continue to affect this immigrant population today. Finally, this chapter reviews the reality of being undocumented to better illustrate the everyday challenges these students face trying to attain higher education in the current U.S. environment.

Chapter three delineates the theoretical framework that grounds this thesis. This chapter incorporates a brief discussion on the three main assimilation theories. Following this I recognize criticisms and possible shortcomings of the chosen theoretical framework. I conclude with a defense of why the chosen model is best suited to address this research.

Chapter four describes the methodological design of this thesis. This chapter outlines the research questions, participant selection and site, data instrument, and data analysis. This section ends with a description of how the participants' responses were understood during the coding process.

Chapter five is a detailed overview of the major findings of this thesis. This section explicates major themes found in the interviews, redresses the research questions 
for the study, and provides quotes from participants intended to further illustrate this study's purpose.

Chapter six offers a more in-depth analysis of the significant findings. In this section the interconnectedness of the findings are discussed. Additionally, this chapter highlights the study's contributions to the area of immigration, and the current political movement concerned with undocumented immigration. I then address the limitations of the study and discuss why further research is important and the direction it should take. 


\section{Chapter II: Literature Review}

While literature on undocumented youth exists, it is far from exhaustive. There are many factors that influence research on this participant group, from age, education, and gender to country of origin, reason for unauthorized entry, and city and state location. Indeed, it has taken education, legislative and judicial communities some time to recognize the realities and struggles of this population. The unique experiences of undocumented Hispanic/Latino students' places pressure on lawmakers and scholars alike in addressing the situation. However, most research lacks the description of this experience from the students' point of view. Accordingly, this study aims to provide a more complete picture of how undocumented students perceive their opportunities for education; the barriers and fears they have faced or will face; and how they manage their undocumented status when it comes to school, work, and the formation of goals and future plans.

\section{Undocumented Immigration}

According to Gonzales (1999), despite their labor migration stream dating back to the early twentieth century, Mexicans are still included alongside new immigrant groups. Realistically, Mexicans have shared a migrational relationship with what is now the United States for centuries. Mexican culture emerged from the ruins of Aztec civilization and from centuries of interactions with the Spanish. This culture followed the Spanish colonial frontier northward, settling in what became the Southwestern United States (Gonzales 1999).

As maintained by Hing (2004): 
What is now the southwestern United States was a destination of Spanish explorers a decade after Hernan Cortés's conquest of the Aztecs in 1519.Over the centuries, these early explorers were followed by settlers who located primarily in present-day New Mexico and to a lesser degree in areas that now comprise California, Texas, and Arizona. (P. 115-116)

Mexico took control of the entire territory in 1821, including all of California, Texas, New Mexico, Arizona and parts of Utah, Nevada and Colorado, when it declared its independence from Spain. Prior to Mexico's control over the area in 1821, these territories were a Spanish colony known as New Spain. For the three centuries between 1519 and 1821, New Spain was populated by Spanish and Mexican settlers. Judging from a lack of historical confrontations, Spanish and Mexican settlers maintained a dominant presence in the territories and sustained working relationships with U.S. settlers and citizens on the American side of the boundary.

Spurred on by America's quest for land expansion, Texas was annexed by the United States within twenty-five years. The belief that America's influence was designed by God to spread westward and southward was known as manifest destiny. Hing argues that racism drove the belief in manifest destiny (2004):

Native Americans were perceived as savages best confined to the small areas of the west. Latin Americans were seen as inferior peoples, best controlled or conquered. Thus, the same racism that justified slavery in the South and discrimination in the North supported expansion in the West. (P. 116)

As territorial expansion surged forward under President James K. Polk, following the successful annexation of Texas in 1845, American and Mexican relations became increasingly hostile. In an aggressive move, Polk ordered a militarization of the "claimed but contested" U.S-Mexico border, and later attempted to purchase "a huge tract of land 
in the Southwest from the angry Mexicans, which ultimately failed (Hing 2004: 117). Following this failure, Mexican and U.S. forces became engaged in violent and bloody disputes over the disputed territory, which led Congress to grant Polk's declaration of war in May of 1846.

The Treaty of Guadalupe Hidalgo was signed in February of 1848, with a victorious United States gaining California and New Mexico (which included present-day Nevada, Utah and Arizona) and having the Rio Grande recognized as the southern boundary of Texas. Hing (2004) states that, “This amounted to 55percent of Mexico’s territory. In return the American government agreed to settle the claims of its citizens against Mexico and to pay Mexico a mere \$15million” (p. 117).

This is where the divide between Mexican immigration and U.S. policy begins. Following the treaty of Guadalupe Hidalgo, many Mexicans continued to think of the newly claimed territories as Mexico's. In fact, Mexicans and Americans paid little attention to the newly created international border, which was unmarked and remained wholly unreal to most. Hing (2004) argues that, "In essence, the boundary was at first an artificial one and did not effectively separate the new U.S. possessions from those South of the border" (p. 118). As a result, Mexicans continued to cross the border, and "border areas constituted one economic region... [where] miners, shepherds, and seasonal workers traveled in both directions to fill fluctuating labor demands" (Hing 2004: 118). This obliviousness was encouraged in order to maintain mutual economic advantage.

The first significant migration wave from Mexico to newly acquired U.S. regions began in the 1880's in response to the labor demand in railroads, mining, and agriculture. 
This migration wave was spurred on by a previous exclusion act, which excluded Chinese immigration. In 1868 the United States and China entered into an agreement known as The Burlingame Treaty. China agreed to end its strict emigration policies, and the United States was eager to open up new channels of trade following the Civil War. In 1870, just two years after the passage of The Burlingame Treaty, growing anti-Chinese sentiment in the West clashed with the desire for Chinese labor and trade. Congress amended the 1790 Naturality Act to deny Chinese the right to become naturalized citizens, because of their "undesirable qualities" (Hing 2004: 36). According to Hing (2004), "By 1882, the Republican-controlled Congress pushed for exclusion of Chinese" (p. 37). The Chinese Exclusion Act was enacted May $6^{\text {th }}, 1882$. The law excluded laborers for ten years, effectively cutting off all Chinese immigration. This is significant because it explains the ebb and flows of migration patterns in the United States.

This exclusion act resulted in the increased demand for cheap immigrant labor, drawing greater attention to the United State's young and susceptible southern neighbor. Mexico was ideal for migrational labor due to its close proximity and therefore cheap travel and maintenance. Following the exclusion of the Chinese, widespread and longdistance Mexican migration began. Agricultural expansion created the demand, and large numbers of Mexican workers found jobs in the United States with the help of an elaborate system of recruitment and support (Hing 2004).

In 1882 the U.S. federal government attempted to regulate Mexican immigration. They first imposed a head tax of fifty cents on each immigrant entering the country. The 1882 act, after being supplemented in 1885 and 1887, forbade anyone from paying for an 
immigrant's transportation to the United States in return for labor, and in 1888 an amendment provided for the deportation of any laborer found to be in violation of the act within one year (Hing 2004). Hing (2004) states that, "What emerges from this brief account is American involvement in a pattern of recruitment designed to service the proclivity of American employers to hire cheap, temporary laborers" (p. 121).

From 1910 to 1920 , approximately 200,000 Mexicans were admitted to the United States, many brought to fill the need of expanded demand for cheap labor in response to growth in mining, railroads, and agriculture. There is evidence that Mexicans were considered to be less troublesome than other potential immigrant groups. López (1981: 615) maintains that Mexicans were described as "not socially or industrially ambitious, like European and Asiatic immigrants"; they “can't do white man's work [and thus] compete little, if at all, with white labor" (López 1981: 615), and moreover, they were distinct from the southern blacks because they were not permanent, did not acquire land and remained nomadic (López 1981: 657). As long as Mexican's participation in the workplace was economically efficient, their temporary presence was to be encouraged and tolerated.

As indicated by Hing (2004), "Events in the decade after World War I provide evidence that American recognition of Mexican labor's value matured from appreciation into economic attachment" (p. 122).

Hing goes on to state that (2004):

In the face of a post-World War recession, an increasingly powerful domestic labor movement, and mobilized restrictions sentiment, the success of Southwestern employers during the 1920's was remarkable. So 
too was their intricate and ingenious domestic strategy that had two compatible goals: first, gaining federal approval for continued immigration law exceptions for temporary Mexican labor, and second, keeping the migrant labor pool large, fluid, and unorganized.(P.123)

Employers drove off domestic workers through both indifference and design. Employers made the work more difficult and hazardous than necessary, and actively neglected to maintain labor camp grounds, buildings, and facilities. This resulted in greater injury, increased health hazards, and deplorable conditions for laborers. Suffice it to say; employers successfully stigmatized the jobs as being beneath white Americans, allowing them to maintain control over a cheap and expansive labor source.

It was not until 1929, and the crash of the economy that xenophobic notions resurfaced. But when they did, it was immediate and intense. Repatriation programs were instituted to encourage documented Mexicans and U.S. citizens of Mexican descent to immigrate to Mexico. The intent was threefold: return indigent nationals to Mexico; save welfare agencies money; and create jobs for real Americans (Balderrama and Rodríguez 1995: 17). Following threats of physical violence, many Mexicans abandoned jobs and homes, taking trains, cars and buses southward to Mexico. As recorded by Balderrama and Rodríguez (1995), the U.S. Labor Department reported that two million returned to Mexico in a fifteen-month period.

As the economy grew stronger with the approach of World War II, many of the Midwestern laborers who had matriculated to fill the space of cheap Mexican labor relocated to better-paying industrial jobs and the need for cheap labor was renewed. In 
1942, the Labor Importation program was organized, more commonly referred to as the Bracero program.

As indicated by Hing (2004):

Unlike previous measures, the treaty purported to regulate the employment of Mexicans as temporary agricultural workers through qualitative and quantitative provisions. Many of these provisions were mandated by new Mexican law enacted in response to the pernicious effects of the previous decade's repatriation; others were included to safeguard two nations' national interests. (P.126)

Unfortunately, the federal government deserted their supervisory role early on, resulting in a lack of the government guarantees that were part of the Bracero program agreement. Taking advantage of the governments' lack of supervision, employers recruited more aggressively than before and swiftly legalized undocumented workers already in the United States. Despite the end of the war in 1945, and the expiration of the special wartime legislation in 1947, the Bracero program continued until 1964, employing nearly five million Mexican workers.

Unauthorized immigration still occurred during the Bracero programs reign. Despite the economic advantages of the program, employers could still avoid the few burdens imposed upon them by using undocumented workers. The legal Bracero program encouraged, though indirectly, undocumented immigration. Employers took advantage of the circumstances and recruited Mexicans who willingly traveled to the United States, saving taxpayers the cost of transporting them, and benefiting employers more than the legal contracted labor. While this large scale recruitment of undocumented cheap Mexican labor took place in Mexico, U.S. lawmakers did their very best to ignore one of 
the more obvious means of curbing undocumented immigration; sanctioning employers of undocumented laborers.

As a result, immigrant workers bore the brunt of the blame, and in 1954 over a million undocumented Mexicans were deported as part of an INS initiative. The defeat of the Bracero program in 1964 is notable because from that point forward, cheap labor became exclusively undocumented. So far, it is clear that unauthorized Mexican immigration did not exist until the 1880's, when the United States first tried to, unsuccessfully, regulate Mexican immigration. Tradition, inconsistent immigration policies, and unenforced immigration policies influenced the Mexican immigration issue we see today. After centuries of free migration, and a century of vigorous promotion, Mexican workers provided an adequate pool of potential workers willing to migrate illegally to the United States in order to benefit from the work opportunities abundantly advertised.

\section{Target Immigration Policies}

While the undocumented population is actually diverse, consisting of youth from Mexico, Central America, South and East Asia, South America, Canada, the Middle East, the Caribbean, and Europe, the majority of this population hails from Latin America. Nearly $75 \%$ of all undocumented youth are of Latin American descent, and the greater portion of this segment is Mexican (Gonzales 2009). This is due to the fact that Mexico and the United States share a geographical border with a long history characterized by ongoing and massive labor recruitment of low-wage Mexican migrants for the U.S. labor force and a persistent social and legal exclusion of Mexicans in communities and schools 
(Camarillo, 1979; Gonzalez and Fernandez 2003). Moreover, Mexico has become a gateway for South and Central American immigrants.

In 1882 the U.S. federal government attempted to regulate Mexican immigration, and in 1888 an amendment provided for the deportation of any laborer found to be in violation of the act within one year, resulting in the first recorded removal policy targeting Mexican migrants. What has proceeded from that point on is a series of poorly devised immigration laws aimed at keeping Mexican immigrants out, mitigated by brief intervals of "authorized" migration in times of crisis (such as the Bracero program). In 1924 Congress signed into law the Reed-Johnson Act, which imposed a numerical quota system for immigration. While this act excluded Mexico and Canada, 1924 was also the year that the Border Patrol was created. 1924 was a year of firsts; the overall restriction and management of U.S. immigration for the first time, and the start of U.S.-Mexico border patrol designed to emphasize the boundary between the two countries for the first time.

Gonzales (2008) argues that since the Immigration reform and Control Act (IRCA) of 1986, limitations for undocumented immigrants have become progressively higher in number. Designed to control and deter "illegal" immigration to the United States, its major provisions stipulate legalization of undocumented immigrants who had been continuously unlawfully present since 1982, legalization of certain agricultural workers, and sanctions for employers who knowingly hired undocumented workers, and increased enforcement at U.S. borders (U.S. Department of Homeland Security 2013). 
Following IRCA, the Illegal Immigration Reform and Immigrant Responsibility Act of 1996 (IIRIRA) changed what was formerly referred to as "suspension of deportation" to "cancellation of removal" (Gonzales 2008: 108). Under IIRIRA, a detainee is required to have ten years of residence prior to initiation of proceedings, good moral character, cannot have been convicted of a crime, and must show "exceptional and extremely unusual hardship" to U.S. citizen or legal resident parents, spouse, or children (Gonzales 2008: 108).

According to Gonzales (2008), this was a dramatic change. Before 1996, "suspension of deportation" provided the detained a form of relief from deportation. In order to qualify, the immigrant in deportation proceedings had to have been in the United States for at least seven years, be of good moral character, and [their] U.S. citizen or legal resident parents, spouse or children would suffer "extreme hardship" as a result of the deportation" (Gonzales 2008: p. 108).

As stated by Gonzales (2008):

The 1996 laws also restricted undocumented students' ability to pursue higher education. First, under the Federal Personal Responsibility and Work Opportunity Reconciliation Act of 1996 (PRWORA), undocumented students were rendered ineligible to receive any aid from the federal government, such as Pell Grants and federal student loans. PRWORA also prevented states from offering public benefits to undocumented students unless the state passes a statute expressly qualifying undocumented students for such benefits. Second, IIRIRA barred states from extending benefits on the basis of residency to undocumented students unless the same benefit is offered to all U.S. citizens regardless of their residency. (P. 108-109)

This is currently being addressed, and to date, fifteen states provide in-state tuition to undocumented immigrants; California, Colorado, Connecticut, Illinois, Kansas, 
Maryland, Minnesota Nebraska, New Mexico, New York, Oklahoma, Oregon, Texas, Utah, and Washington. The majority of universities in the remaining thirty-five states deny in-state tuition to undocumented Hispanic/Latino students. (National Immigration Law Center 2013).

Related immigration policies in the late 1990's include the U.S. Equal Employment Opportunity Commission (EEOC), which ruled that unauthorized workers who are subjected to unlawful employment discriminations were entitled to the same relief as other victims of discrimination, such as back pay and the use of civil rights violations as a defense. Gonzales (2008) notes:

The EEOC protected undocumented immigrants who were filing suit under the logic that it would ultimately make undocumented workers less attractive to employers if the number of advantages to hiring them were diminished. In the decade following many of these rights have disappeared and interior enforcement efforts have increased dramatically. As a result, increased deportations have placed a great deal of fear in undocumented immigrants and they are less likely to exercise any remaining rights they may have. (P. 109)

This only served to further disadvantage undocumented immigrants. Due to a lack of enforcement or consistent treatment under this commission, and increased deportations, undocumented workers were more likely to be targeted if attempting to report discrimination or violations. Employers used this knowledge as a weapon, knowing full well that an undocumented immigrant was more likely to be deported than to receive any type of benefits.

By way of these legislative acts, Congress has engaged in a lasting form of "legalized racialization", as defined by Ngai (2004), casting Mexican and 
Hispanic/Latino immigrants as "permanently foreign and unassimible to the nation" (p. 4). This racial history informs sentiments that epitomize the current national attitude towards persons who appear to be Hispanic/Latino immigrants. It is this racially hostile attitude that makes the lives of these undocumented students so hard. They are exposed to harassment, derision, neglect and outright hostility in their communities, their schools, and their work sites. Every aspect of their lives is influenced by this persistent "legalized racialization".

If any further proof is needed of how immigrant identity is racialized by way of the laws of the land, consider Arizona's recent Senate bill, S.B. 1070.

According to the Office of Arizona's Governor Janice K. Brewer, S.B. 1070 is a "secondary enforcement" law (2010). S.B. 1070 requires that there must first be a "lawful stop, detention or arrest made by a law enforcement official or a law enforcement agency... before an officer can ask a person about their legal status. Only then can they inquire about immigration status - but only if that individual's behavior provides 'reasonable suspicion' that the person is here illegally" (Office of Governor Janice K. Brewer 2010).

"Reasonable Suspicion" in this case may only be skin deep. There have been numerous complaints of increased police harassment and racial profiling against persons who "look" like Hispanic/Latino undocumented immigrants, regardless of documentation status, in the state of Arizona since the enactment of this bill.

These racialized identities that emerge from nativism in the United States are at odds with a competing demand for cheap labor provided by undocumented immigrants in 
the United States (Schmidt Camacho 2008). Hispanic/Latino immigrants migrate to the United States through extralegal means to find jobs and opportunities not afforded them in their home countries. Parents make the decision to migrate to the United States, leaving behind the majority of their family and friends, and in the case of the 1.5 generation, bringing their children with them. Families that are desperate or disadvantaged enough to leave everything behind and migrate to the United States are victims of a growing capitalist economy. With corruption in the Mexican government, and outsource labor the most rewarding of employment, parents view the United States as their only means of providing a more stable environment with socioeconomic opportunities for their children. This leads them to come to, or stay in the United States without legal authorization-and plenty of extralegal sources of work provided by employers in agriculture, the food industry, construction, the hotel industry and janitorial services- a decision they hope will afford them and their children opportunities they cannot find in their own country.

The parents' estimation is well founded given the opportunities provided to children in the United States. Despite their undocumented status, undocumented students have legal access to public education from kindergarten through high school graduation. In 1975, Texas enacted a state law that enabled its public school districts to charge tuition to parents of undocumented children. Under the direction of Superintendent James Plyler, School officials in Tyler, Texas, began charging \$1,000 annual tuition for each undocumented student (Olivas 2005). 
In 1978, a U.S. district judge found both the state law and Tyler's policy unconstitutional, holding that they violated the 14th Amendment's equal protection clause. The U.S. Court of Appeals for the Fifth Circuit affirmed the decision.

The Plyler case then went to the U.S. Supreme Court. In 1982, the Supreme Court struck down the Texas statute in a 5-4 decision, also holding that it violated the equal protection clause. The 1982 Supreme Court ruling has barred public schools from excluding undocumented children (Olivas 2005). This, however, only applies to grades $\mathrm{K}-12$.

Undocumented status, however, precludes undocumented immigrants from various certain public services, such as public health services, welfare assistance, and unemployment compensation, depending on the state where they reside. Furthermore, the 1.5 generation is participant to the derision and hostility described previously as a result of "legalized racialization".

While these students are capable, and in many cases, succeed, in excelling at school, and participating in sports, clubs and other youth activities, there is an unfortunate period where the reality of living illegally is brought to the forefront. The true tragedy is that it is this time of transition, from childhood to adulthood, that being undocumented disrupts the lives of so many hopeful students (Ngai 2004). This transition is difficult enough for youth, without being complicated by a nagging fear that everything you thought you had can be taken away and everything you wanted to have could be pulled out of reach. 
In 2010, a series of informal interviews for a youth subcultures class at Portland State University were carried out. The focus was on undocumented high school Hispanic/Latino students learning about their status for the first time. The ten interview participants were male, and ranged between the ages of 16 and 19. The most common theme, and also the most disturbing, that came out of these interviews, was the overwhelmingly common depression that fell upon these students when the consequences of their "illegality" were made clear. Juanes, the student described in the introduction, is a perfect example. Other descriptions were feelings of "despair", "frustration", and a loss of motivation to do anything (Roberts 2010). One young man was very descriptive and revealed that he had access to weapons and felt that "there is nothing stopping me from hurting myself. I lost, and there is nothing left" (Roberts 2010).

The political atmosphere is no longer all negative, however. Great strides have been made towards reclaiming some of the rights and privileges undocumented Hispanic/Latino youth were previously stripped of. With continued activism and political involvement there is the potential for a path to citizenship. Already mentioned is the continued push for in-state tuition for undocumented Hispanic/Latino students, but there are recent and continued efforts aimed at granting legal status and citizenship. Deferred Action for Childhood Arrivals was passed in 2012, as an alternative to the more encompassing DREAM Act. Eligible DACA recipients are granted temporary legal status, receive a permit for work, and are able to benefit from a variety of services under respective state laws. DACA is a temporary fix to a much more complicated problem. 
Because DACA was passed in 2012, there is minimal research to consult on this policy's effectiveness and impact at the national, federal, or state levels to date. There are, however, pros and cons that have been identified by various researchers as well as the participants themselves. The Ranchod Law Group has provided a well researched and objective list of the pros and cons of Deferred Action for Childhood Arrivals (2013).

According to law DACA allows undocumented immigrants the possibility to obtain a 2-year work permit, the opportunity to apply for a driver's license, and the increased possibility of being able to obtain auto insurance and a social security card. The work permit is the most significant advantage, as individuals who are not eligible for DACA must either pay a $\$ 380$ filing fee for an Employment Authorization Document, which is only valid for one year, work under the table, work below minimum wage jobs, or get work using false identification which is a crime (The Ranchod Law Group 2013).

Although temporary, there are benefits to DACA. The work permit is a constant for those who receive DACA. The other pros depend on the state of residence. For example, recipients of DACA would be eligible to receive a drivers license in the state of Oregon, and any other immigrant regardless of status as of January 2014 (National Immigration Law Center 2013), but would be denied a drivers license in the state of Arizona. Another pro, which was touched on previously, is the opportunity to travel abroad. There are restrictions on this, including such trips are required to be humanitarian, educational, or work-related, and DACA recipients must file paperwork prior to the date of departure and are encouraged to consult with an attorney to ensure they are able to reenter the United States (The Ranchod Law Group 2013). 
There are disadvantages to Deferred Action for Childhood Arrivals as well. The requirements imposed for DACA deny a large part of the undocumented immigrant community eligibility. According to the Department of Homeland Security (2013) website, the following are the criteria that must be met in order to be considered for DACA:

"You may request consideration of deferred action for childhood arrivals if you:

1. Were under the age of 31 as of June 15, 2012;

2. Came to the United States before reaching your $16^{\text {th }}$ birthday;

3. Have continuously resided in the United States since June 15, 2007, up to the present time;

4. Were physically present in the United States on June 15, 2012, and at the time of making your request for consideration of deferred action with USCIS;

5. Entered without inspection before June 15, 2012, or your lawful immigration status expired as of June 15, 2012;

6. Are currently in school, have graduated or obtained a certificate of completion from high school, have obtained a general education development (GED) certificate, or are an honorably discharged veteran of the Coast Guard or Armed Forces of the United States; and

7. Have not been convicted of a felony, significant misdemeanor, three or more other misdemeanors, and do not otherwise pose a threat to national security or public safety."

A common criticism of this policy by the participants I interviewed was that it

failed to protect parents and older siblings. Multiple participants expressed their desire

to be able to become a U.S. citizen alongside their parent(s), but they fear that with the lack of progress on immigration reform, Deferred Action for Childhood Arrivals is all they will be able to achieve. As it is, DACA is not enough.

Not only does DACA serve a limited percentage of the undocumented immigrant population, but it is also a temporary policy. The Ranchod Law Group (2013) states, "There is always the possibility that a president could change immigration policy and 
revoke grants of deferred action and work permits." There is a very real possibility that a change in governmental control will result in the abolishment of Deferred Action for Childhood Arrivals. In which case, undocumented immigrants will encounter more barriers to education and citizenship. The Ranchod Law Group (2013) completes their list with this statement, "Lastly, there is no right to appeal a decision made by United States Citizenship and Immigration Services (USCIS). If USCIS makes a mistake and you cannot identify and correct the mistake, you could be deported." All things considered, DACA is an improvement for these students.

Prior to DACA, undocumented immigrants had limited work options. Without a Social Security Number, or valid work permit, undocumented immigrants could not legally apply for work. This resulted in undocumented immigrants working under the table, working below minimum wage jobs, or using a fake Social Security number or work permit to secure gainful employment. DACA has greatly improved the lives of eligible recipients, increasing work opportunities, and various other aspects of life. However, DACA is not entirely trusted by the undocumented Hispanic/Latino population.

The Mexican American Legal Defense and Educational Fund (MALDEF) published a user manual in 2012 for undocumented immigrants. This manual explains DACA, how to apply, the costs associated with an application, and applicant eligibility requirements. It also cautions applicants to consult a licensed immigration attorney or a Board of Immigration Appeals (BIA) accredited representative before filing in order to be certain that all eligibility requirements are met (MALDEF 2012). This guide repeatedly 
warns applicants to only apply if they are certain they meet eligibility criteria as DHS has stated that it will put individuals who are denied deferred action into removal proceedings if there is a finding of criminal histories or of fraud in the application (MALDEF 2012).

Also, regardless of whether DHS approves or denies an individual for deferred action, DHS will maintain a record of an individual's presence in the United States. DHS has also stated that while it does not plan on using the information provided in a 2012 deferred action application to place undocumented relatives into removal proceedings, that information may be shared with national security and law enforcement agencies, including ICE and CBP, for purposes other than removal (MALDEF 2012: 27). Such purposes were identified as "to identify or prevent fraudulent claims, for national security purposes, or for the investigation or prosecution of a criminal offense" (MALDEF 2012: 27). Given that DHS or a subsequent DHS administration can change its policy at any time and for any reason, the sharing of such information is suspicious and alarming.

\section{Undocumented Youth: The 1.5 Generation}

Each year, 65,000 undocumented students graduate from high school nationwide (Passel 2003). It is important to consider how their undocumented status affects their available paths to socioeconomic mobility and therefore incorporation patterns in this society. Comprising 20 percent of the child population in the United States, immigrant children and children of immigrants have a "transformative potential" on the country (Alba, Massey, and Rumbaut 1999). Through their level of educational attainment, the 1.5 and second generation will help determine the class status of their ethnic communities. 
The undocumented 1.5 generation is still a relatively new population, as prior to 1942 migration patterns were majorly fluid with men traveling to the United States to work seasonal or temporary jobs. While in the U.S these men sent their wages home to their families, until they returned from their work at the end of the season. With the organization of the Bracero program, greater numbers of young men were imported to the United States to fill the demands for labor, inadvertently disrupting the previous migratory pattern. These young men began bringing their families with them to the United States in order to maintain the family unit, and to reap the benefits of being legally imported workers.

As the Bracero program employed an estimated five million Mexican workers over two decades, it is not surprising that with the end of the Bracero program in 1964 many Mexican workers remained in the United States. Those who did not already have their families with them began bringing their families to the United States. This interruption of the previously fluid migration proved to be irreversible. Following the abolishment of the Bracero Program in 1964, Mexican migration not only increased in volume, but it also had larger numbers of permanent immigrants (Bean, Passel, and Edmonston 1990). Families began migrating to the United States together, drawn to the opportunities America had to offer as much as fleeing from the continued downward spiral of Mexico's government and economy. This resulted in a new generation of Mexican immigrant, the 1.5 generation.

The 1.5 generation is a generation of students who migrate to the United States and carry over the traditions or lifestyle of their home country, and have learned to 
acculturate themselves into the U.S. culture. Gonzales-Berry and Mendoza (2010) argue that the experiences of these children are:

Distinct from those of younger children whose identities are not yet well defined when the family migrates. Adolescence is a moment of crossing, an important identity forming threshold. In addition to the physical and psychological changes involved in crossing this threshold, the individual's sense of identity is also expanding to include a national consciousness... Given the extreme physical and turbulent psychological changes involved in crossing the adolescence threshold in a new country, the process may be likened to a trauma not unlike that experienced by adult migrants as they move from a familiar and secure geo-social and political space to a foreign and frequently hostile environment. (P. 213)

Besides the stress of relocation and development, undocumented youth's transformative potential is severely limited by legal barriers. Rumbaut and Ima (1988) explain that the 1.5 generation faces two challenges: first, the transition from childhood to adulthood, and second, acculturation, or the transitioning from one culture to another. These challenges, matched with an undocumented status, are indicative of what an undocumented student's life is like. It is precisely this reality that this research is interested in and how this reality shapes these students' lives and their future endeavors.

\section{The Reality of Being Undocumented}

Upon realizing their status as an "undocumented student", students undergo a period wrought with emotional anguish and anxieties. Goals are adjusted, dreams are reconfigured and hopes for the future are temporarily inconceivable. What many students fear is that they cannot attend college. Without a college degree, and a social security number, they understand their fate to be that of their parents. For the students undeterred by this new reality of being undocumented, there are barriers to higher education, and 
risks in working without a social security number. If caught with fabricated identification, the risk of deportation is high, let alone being charged and convicted of a felony. One critical service denied to undocumented students is federal financial aid. This becomes important after high school because in most states, both public and private universities classify them as either international or out-of-state students and charge them tuition three to seven times higher than that of legal residents or U.S. citizens (National Immigration Law Center 2013).

Consequently, the costs of attending college are often prohibitive. Unless a student manages to earn enough scholarship dollars to cover the entire cost of tuition, books, transportation, housing, and/or living expenses, they are required to earn their degree class by class, most often working full time in a minimum wage job to afford the costs of attendance. The hard truth is that even if they are able to beat these insurmountable odds, for many fields, they will still need a social security number to be able to attain a position worthy of their degree.

Undocumented immigrants, particularly those with limited human capital, face the worst possible context for reception upon arrival in the United States. Besides the challenges and limitations they face as a result of their extraordinarily low human and economic capital, discriminatory policies by federal and state legislature fail to grant them legal status and, as a consequence, other benefits such as resettlement assistance, legal residency, and most social protections - including welfare and unemployment benefits (Chávez 1998). 
The vast majority of Hispanic/Latino immigrants in Portland metro are incorporated into menial low-wage service occupations with little to no opportunity for upward mobility. Children of immigrants, then, must achieve entrance into the upper sectors of the economy through educational attainment if they want to avoid reproducing the same difficult living conditions that their parents faced upon arrival (Seif 2004). Educational attainment is crucial to the future success of the most recent Hispanic/Latino immigrants.

Resiliency, or "immigrant optimism", is a surprising factor when considering the experiences of undocumented Hispanic/Latino youth. Coined by Kao and Tienda (1995), the "immigrant optimism" hypothesis built upon Ogbu's work with voluntary vs. involuntary immigrants (1991). Borrowing much of Ogbu's (1991) language, the "immigrant optimism" hypothesis argues that international migrants are "self-selected" and "predisposed" to adapt to the host society, and although many find themselves at the "bottom of the socioeconomic ladder initially," they expect that the situation is temporary, and they or their offspring will experience upward mobility. Also, these immigrants tend to overcome difficulties and obstacles in their host country because their frame of reference is their home country, where they often faced harsher environments. "Voluntary" immigrants also view their "adjustment problems as temporary, and therefore are more creative in inventing pragmatic solutions to their current predicaments" (Kao and Tienda 1995: 5).

Immigrant optimism also posits that differences between immigrant and native parents are the essential factors to explaining generational differences in performance 
among youth. It goes on to define the immigrant, the $2^{\text {nd }}$, and the $3^{\text {rd }}$ generations, and fails to recognize the 1.5 generation. Immigrant optimism suggests that $2^{\text {nd }}$ generation students are best positioned to succeed academically because "they both benefit from the optimism of their immigrant parents and are more proficient in English" (Kao and Tienda 1995: 15), although immigrant optimism does maintain that immigrant students and $2^{\text {nd }}$ generation students perform as well as their peers, and outperform $3^{\text {rd }}$ generation students.

Although Kao and Tienda (1995) did not apply this idea of immigrant optimism to undocumented Hispanic/Latinos specifically, there is anecdotal evidence to support the theory that undocumented Hispanic/Latinos benefit from immigrant optimism just as much, if not more, than their documented peers. Unfortunately, after the $2^{\text {nd }}$ generation this cultural capital becomes compromised. Discrimination, racism, and a sense of disillusionment conspire to work against children of the $3^{\text {rd }}$ generation and beyond, with consequences for the entire ethnic community.

Clearly, much attention has been given to this population in recent years. Policies have been proposed at all levels, legislation has been passed in states, at the national level legislative action is being debated, and yet there is still something missing. Gonzales (2008, 2009) and Abrego (2006) both incorporate this missing element in their work; the voices of these undocumented students. As this research likewise boasts the inclusion of undocumented students' perspectives, a brief comparison is in order to highlight the similarities and differences between this research and the research conducted by Gonzales (2008, 2009) and Abrego (2006). 
Similarities between this research and those of Gonzales and Abrego are the identifications of barriers to higher education, and the identifications of social supports that positively influenced the pursuit of higher education. Barriers identified by participants in this research and in Gonzales and Abrego's research are a lack of financial assistance, discrimination based on race/ethnicity, as well as documentation status, fear or threat of deportation, and frustration and anger with the prolonged process of completing higher education. This is especially significant when taking into account that Gonzales and Abrego conducted their research prior to 2012, and the passing of DACA. That participants in this research provide similar if not identical responses concerning barriers to higher education to those of Gonzales and Abrego's participants, even after receiving DACA, illustrates the pervasiveness of the identified barriers.

A lack of financial assistance was easily the most common barrier identified by participants in all four studies (Roberts, 2014; Gonzales 2008, 2009; Abrego 2006). Participants in all four studies also provided similar descriptions of how this barrier affected their pursuit of higher education. Again in all four studies, participants readily identified discrimination and the threat or fear of deportation as strong barriers to the pursuit of higher education, providing various examples of family members, friends, and even personal accounts of deportation and experiences with discrimination. Participants in all four studies similarly expressed frustration, anger and anxiety over the prolonged process of competing higher education degrees.

Participants in all four studies also described personal accounts where they felt frustration at being undocumented when they compared their opportunities and 
experiences with those of documented peers and family. Numerous participants from each study expressed envy and resentment for documented peers and family who had been lazy and less competitive in high school, but who qualified for admittance to fouryear universities. Numerous participants expressed feeling cheated at having competed so hard in high school and to have worked so hard only to be passed up by less than stellar students.

There were also many similarities in the social supports, or bridges, identified by participants in all four studies. The most common were family, community, mentors, and resiliency. The importance of family is illustrated quite plainly through the countless references and discussions participants made in all four studies. The importance of parents and their influence over student's lives is repeatedly recognized, as well as the sense of security and stability that family provides for participants. Family is likewise recognized for providing a multitude of supports, including food, shelter, respite, job opportunities, and financial assistance. Community is recognized as a great support more strongly in Gonzales and Abrego's research, but this may be due to the larger scale of their studies. This research does provide reference to the importance of community, and several examples are listed from participant interviews, but Gonzales and Abrego have much richer representations of community support, including but not limited to various religious, school, and athletic programs.

Mentors were again a significant factor identified by participants for the positive influence of pursuing higher education. Participants in all four studies described different mentors and the characteristics and abilities that made them influential and successful. 
Finally, resiliency is addressed in all four studies to varying degrees, but all in all, it is identified as an important factor for undocumented students in the pursuit of higher education. Resiliency, or immigrant optimism, is illustrated in participant responses in various sections of each study, which lends support to the theory that it is a predictable factor and not novel to this research.

There are major differences between this research, and those of Gonzales and Abrego, however. The most leading difference is between participant responses in this research and those in Gonzales' work. Responses provided by participants when recounting how they discovered their undocumented status and how it made them feel between the two studies was significant. In Gonzales' research, multiple participants expressed anger and attributed blame to their parents for causing such turmoil in their lives. No participants in this research blamed their parents for their undocumented status, and no participants expressed anger towards their parents for keeping this from them, or for causing them to bear such a status. This could stem from the difference in ages between Gonzales’ participants and the participants of this research; Gonzales had younger participants, which could mean they were still recovering from the discovery or re-introduction of their status, while participants in this research would have had more time to confront their status and decide what to do. Regardless, it is a major difference between the two works.

This research was more concerned with the reactions and feelings participants' experienced when they discovered or were re-introduced to their undocumented status than the research of Gonzales and Abrego. While all four studies make reference and 
address this period of the participants' lives, this research illustrated a greater interest in the period. This period was of great interest for this research due to its influence over participants' physical, emotional and mental health. Another major difference was the distinguished influence that parents had over the stability and security of their children's health and their ability to navigate the period of disillusionment that was identified in this research. As opposed to Gonzales and Abrego's research, this research argues that parents have a great deal of influence over their children's ability to accept and understand their undocumented status, and implicates methods and actions parents can use to better support and serve their children.

Finally, the greatest differences between this research and those of Gonzales and Abrego are the size and time frames of the research, and the geography. Gonzales and Abrego both have greater sample sizes and spent longer periods of time interacting with, and observing undocumented students in various capacities. This undoubtedly allowed greater depth to their research, and increased the transferability of their research. It also allowed greater diversity of their participant pool, which supplied the ability to make comparisons between different segments of the undocumented population.

One thing this research can contribute that Gonzales and Abrego cannot is a closer look at undocumented Hispanic/Latino youth in Oregon. This is significant as much of the research into this population has taken place in largely Border States; Texas, Arizona, California and New Mexico. Gonzales and Abrego conducted their research in large, California cities, where gang presence and violence was highly visible, and where ethnic diversity and migration are commonplace. Participants in each of their studies 
made references to gang activity or violence in the neighborhoods where they lived and attended school. Gang presence is specifically addressed due to its prevalence in low income neighborhoods and areas, which is where the vast majority of undocumented Hispanic/Latino youth reside. As previously mentioned, undocumented Hispanic/Latinos face the worst possible context for reception upon arrival in the United State, which almost certainly relegates them to low-income housing in poor neighborhoods.

It is no secret that high poverty neighborhoods attract and breed violence, crime, and deviance. Gangs are responsible for a large portion of violence, crime and deviance, which creates a hostile environment for neighborhood residents. It is for this reason that gang presence is specifically used as a comparison tool. According to the FBI's 2011 National Gang Threat Assessment, California, Arizona, New Mexico and Texas have approximately six or more gang members per one thousand people, three to four gang members per one thousand people, six or more gang members per one thousand people, and three to four gang members per one thousand people, respectively. Oregon has two to three gang members per one thousand people.

As illustrated in the following table, California hosts three hundred and thirty-six different gangs; Arizona has seventy-one different gangs; New Mexico has the lowest of all the Border States, with an estimated twelve different gangs present; Sixty-eight gangs are present in Texas; Oregon has twenty different gangs present. Oregon's gang presence and level of violence is scarce, with just over 1,500 individuals identified as gang members or arrested for gang activity in Washington County in the year 2013 (Garret 2013). In October 2013, just over one hundred gang related incidents had been reported 
to the Portland Police, including six gang related shootings (Bernstein 2013). Clearly

Portland, Oregon is not without gang violence, presence or activity, as the number of reported gang related incidents has increased, but in comparison to the Border States, Oregon gang presence is relatively low.

\begin{tabular}{|c|c|c|c|c|c|}
\hline & CA & $\mathbf{A Z}$ & NM & TX & OR \\
\hline \multicolumn{6}{|l|}{2013 Census Data } \\
\hline White Only \% & 39.0 & 56.7 & 39.4 & 44.0 & 77.5 \\
\hline Hispanic/Latino \% & 38.4 & 30.3 & 47.3 & 38.4 & 12.3 \\
\hline Black/A.A. $\%$ & 6.6 & 4.6 & 2.5 & 12.4 & 2.0 \\
\hline $\begin{array}{l}\text { Asian/Pacific Is. } \\
\%\end{array}$ & 15.8 & 3.5 & 1.8 & 4.4 & 4.5 \\
\hline Total Population & $38,332,521$ & $6,626,624$ & $2,085,287$ & $26,448,193$ & $3,930,065$ \\
\hline \multicolumn{6}{|c|}{2011 FBI Gang Assessment Data } \\
\hline $\begin{array}{l}\text { Gang Members } \\
\text { per } 1000 \text { people }\end{array}$ & 6 or more & 3 to 4 & 6 or more & 4 & 2 to 3 \\
\hline $\begin{array}{l}\text { Estimated Number } \\
\text { of Gang Members } \\
\text { for Total } \\
\text { Population }\end{array}$ & 229,992 & 26,504 & 12,510 & 105,792 & 11,790 \\
\hline $\begin{array}{l}\text { Estimated Number } \\
\text { of Gangs Present }\end{array}$ & 336 & 71 & 12 & 68 & 20 \\
\hline
\end{tabular}

As reported by the 2011 National Gang Threat Assessment:

The US Southwest Border region represents a continuing criminal threat to the United States. The rugged, rural, and porous area along the nearly 2,000 miles of contiguous US-Mexican territory invites widespread criminal activity, including drug and arms trafficking, alien smuggling, human trafficking, extortion, kidnapping, and public corruption. US-based gangs, Mexican Drug Trafficking Organization(MDTOs), and other criminal enterprises in both the United States and Mexico are readily exploiting this fluid region and incur enormous profit by establishing wide-reaching drug networks; assisting in the smuggling drugs, arms, and illegal immigrants; and serving as enforcers for MDTO interests on the US side of the border. Violence in Mexico-particularly in its northern Border States - has escalated with over 34,000 murders committed in Mexico over the past four years. While intensified scrutiny from Mexican 
law enforcement has forced significant disruptions in several dangerous MDTOs, such disruptions have also served to disrupt the balance of power among these organizations. This has prompted drug cartel rivalries to employ more aggressive tactics as they attempt to assert control over the Southwest border region and its highly lucrative drug trafficking corridors. Although the majority of the violence from feuding drug cartels occurs in Mexico, Mexican drug cartel activity has fueled crime in the porous US Southwest Border region, where easy access to weapons, a high demand for drugs, ample opportunity for law enforcement corruption, and a large Hispanic population ripe for recruitment and exploitation exists. (P. 39)

This inaccessibility to the U.S./Mexico border is another difference between this research and that of Gonzales and Abrego. Not only does Oregon's physical distance from the border influence lower gang activity, but it is a significant influence for the Hispanic/Latino population who find themselves culturally isolated.

Demographically, Oregon is a predominantly White state. According to the 2013 U.S. Census, $77.5 \%$ of Oregon's population identified as White only, nonHispanic/Latino. Only $12.3 \%$ of Oregon's population identified as Hispanic/Latino. As evidenced by Table 1 above, the Border States are demographically more diverse, with higher rates of Hispanic/Latinos. With the signing of the Treaty of Guadalupe Hidalgo in 1848 , roughly eighty thousand Mexicanos inhabiting the now Border States and Southern Colorado were granted American citizenship (Gonzales-Berry and Mendoza 2010: 12-13). According to Gonzales-Berry and Mendoza (2010), the United States considered the colonized Mexicans as "inferior and deserving of condescension and discrimination.

These colonized Mexicans and, subsequently, all future immigrants from Mexico... would be viewed as a people inassimilable by their 'nature'... and thus 
undeserving of fair and just treatment" (p. 13). In the Border States, this legacy of colonization constructed the Mexican identity and the foundation which determined the treatment of this population. Gonzales-Berry and Mendoza argue that in removed areas such as Oregon, "mexicanos would bear the brunt of racialized thinking, but their experience would be somewhat different from that of mexicanos in the Southwest" (2010: 13). Hispanic/Latino immigrants have a propensity for forming a culturally distinct national/ethnic group in order to provide a sense of community and belonging, and in the Border States, these culturally distinct groups serve as an extension of the mother country and its familiarity and traditions. However, the experiences of Hispanic/Latinos in Oregon are qualitatively different from the "identity formation of their compatriots in California and the Southwest" (Gonzales-Berry and Mendoza 2010: 14). According to Gonzales-Berry and Mendoza (2010):

In Border States there is always a sense among Mexicanos of the contiguity of the mother country, of Mexican culture as a foundational substratum... and of the fact that Spanish is not a foreign language. In Oregon, mexicanos are more conscious of the distance that mediates between them and the homeland, of their outsider status, of the fact that their language and culture are indeed viewed as foreign. The border linking Mexico and the United States serves as a concrete iconic reminder of political separation but so too does it serve as powerful space of bilingual and bicultural linkage that nurtures a strong ethnic identity among both the colonized and immigrants along the border. That political border is too distant for mexicanos in Oregon to rally around it as a symbolic unifying idea. (P. 14)

In Oregon, Hispanic/Latinos have a different kind of border, which Gonzales-Berry and Mendoza refer to as a "socio-spatial line that mediates between the reality of their lives at home and that of the public space of mainstream culture" (2010: 14). This socio- 
spatial line is intensely "personal and psychological", and functions as a constant reminder of their cultural isolation as well as their separation from dominant society (Gonzales-Berry and Mendoza 2010: 14). Furthermore, Oregon's lack of a colonized population also means the absence of "culturally constructed economic, social, and political infrastructure created by a people rooted in a space they could claim as their own, as is the case in the Border States" (Gonzales-Berry and Mendoza 2010: 14). This resulted in early mexicano settlers in Oregon being unable to benefit from the protective values of belonging. Nevertheless, Hispanic/Latino immigrants in Oregon have not had to contend with the stigma of being a colonized population like the Hispanic/Latino population residing in the Border States.

These differences in demographics, gang presence, and racialized views set this research apart from that of research conducted in California and other Border States. These differences illustrate historical dissimilarities between Oregon and the Border States, as well as different contexts of reception, treatment, and experiences. As of right now, there is no prediction as to whether the geography of this research will produce different results than those found in Abrego and Gonzales's work. But it is something to consider. Perhaps geographical location lends more or less to the degree of "legalized racialization", perhaps not. Either way, this research proposes to add the voices of undocumented youth from the Portland metro area of Oregon to the literature. This field needs more voices, and more perspective from the students who are affected most by the cause and effect of growing up as undocumented youth. 


\section{Conclusion}

This brief review of the literature on Hispanic/Latinos and undocumented immigration highlights: Hispanic/Latino relations with the United States; the start of Mexican migration into the United States; immigration policy targeted at Mexican migration; repeated recruitment of Mexican labor; changes in migratory patterns as a result of the ever evolving relationship between the United States and Mexico. It also draws attention to the recent history of the 1.5 generation, describing how changes in migration led to the immigration of entire families as opposed to the previous migration of unencumbered men and women. This review lays out a timeline for the history of U.S.-Mexico migration, which emphasizes the tenuous relationship Mexican laborers had with the United States.

Examining important historical dates, specific immigration policies and U.S. employer relations with Mexico helps to explain the motivation Hispanic/Latino families have for entering the United States unauthorized. This review also helps to illustrate how over the course of history, undocumented Hispanic/Latino immigrants have been subject to unjust and discriminatory laws. It also highlights the changing atmosphere that undocumented Hispanic/Latino students have faced over the decades, cataloguing ever increasing limitations and restrictions to higher education, social services, and occupations. 


\section{Chapter III: Theoretical Framework}

\section{Introduction}

Classic assimilation presupposes that the descendents of immigrants become indistinguishable from the rest of society in their behaviors, characteristics, and socioeconomic outlooks after two to three generations in the host society (Gordon 1964). However, given changes in demographics of current waves of immigration, economic adjustments in the United States, and the new contexts of reception, classic assimilation is no longer adequate in explaining the diverse experiences of immigrants. As a result, assimilation theory has undergone several transformations, and there are now multiple theories of assimilation.

Classic assimilation theory has arguably been optimistic, albeit somewhat ethnocentric, with emphasis on eventual and total integration into the host society. The racial/ethnic disadvantage model takes race and ethnicity into greater account, arguing that language barriers, race and ethnic disadvantages, and cultural ignorance effects assimilation. Lastly, segmented assimilation is a combination of the classic and race/ethnic disadvantage models. Segmented assimilation argues that different segments of immigrant populations assimilate differently. This theory is criticized for being overly pessimistic.

\section{Classic Assimilation Theory}

The classic assimilation theory is best defined as "straight line assimilation", and according to Vasquez, it predicts a step-wise process that begins with cultural assimilation and eventually reaches the destination of racial/ethnic intermarriage and 
changes in racial/ethnic identification, losing ethnic descriptors in favor of "American" ones (2011). The "straight line" version of assimilation theory assumes that all immigrants will experience the same treatment by the host country, and that they will be afforded the same opportunities as host citizens. This theory does not take into account difference in gender, phenotype, sexual orientation, level of education, social movements, documentation status, etc., all of which influence immigrants' perceptions of themselves, their relationship to their ethnic heritage, and their relationship to the United States (Vasquez 2011). In other words, this classic theory of assimilation fails to recognize the assimilation experiences of recent immigrants are more variegated and diverse than the scenarios provided.

\section{Racial/Ethnic Disadvantage Assimilation Theory}

This model argues that "language and cultural familiarity may often not lead to increased assimilation. Lingering discrimination and institutional barriers to employment and other opportunities block complete assimilation" (Brown and Bean 2006). Literature suggests that immigrants compare socioeconomic opportunities in the host country to those in their countries of origin, and with that comparison, such barriers go unnoticed until the second or third generation.

By this time they may realize that full assimilation may be more difficult and take longer than originally presumed. Racism and prejudices play a large role in this assimilation theory, as the context of reception for immigrants of color is drastically different from that of white and "model minority" immigrants. This racism influences an immigrant's ability to assimilate into the host culture. 


\section{Segmented Assimilation Theory}

Portes and Min Zhou (1993) combined elements of both the straight-line assimilation and the ethnic disadvantage perspectives into the segmented assimilation framework. They theorize that structural barriers, such as poor urban schools, cut off access to employment and other opportunities — obstacles that often are particularly severe in the case of the most disadvantaged members of immigrant groups (1993). Such impediments can lead to stagnant or downward mobility, even as the children of other immigrants follow divergent paths toward classic straight-line assimilation. Heavily disadvantaged children of immigrants may even reject traditional assimilation altogether and embrace attitudes, orientations, and behaviors considered "oppositional" in nature, such as an aversion to education.

More advantaged groups may sometimes embrace traditional home-country attitudes and use them to inspire their children to achieve, a process Portes and Zhou (1993) call selective acculturation. Consequently, segmented assimilation focuses on identifying the contextual, structural, and cultural factors that separate successful assimilation from unsuccessful or even "negative" assimilation. Portes, Zhou, and their colleagues argue it is particularly important to identify such factors in the case of the second generation, because obstacles facing the children of immigrants can thwart assimilation at perhaps its most critical juncture.

\section{Conclusion}

Comparing these three models of assimilation theory, the segmented assimilation theory is most appropriate for this research. Undocumented Hispanic/Latino students are 
some of the most disadvantaged members of immigrant groups, and as the classic or "straight-line" assimilation theory neglects the many different experiences immigrants can have in the host country, the segmented assimilation theory appears to be the most adequate model to account for undocumented Hispanic/Latinos experiences of being brown, poor, and without documentation.

According to Abrego (2006), the segmented assimilation framework has been used to examine the educational achievements and incorporation patterns of children of immigrants in various related literature concerning this research problem. The segmented assimilation framework assumes that the assimilation process takes place in the context of a society consisting of segregated and unequal segments. Assimilation among Hispanic/Latino immigrants and their offspring may not only take the form of growing acculturation and parallel integration into the middle class; it may also consist of assimilation into permanent poverty and the underclass, due to limited opportunities for socioeconomic mobility, racial discrimination, and residential segregation (Portes and Rumbaut 2001) .

Segmented assimilation scholars argue that immigrants today are facing structural conditions that did not previously exist. In 1979 Piore argued that U.S. labor market changes and immigration policies had altered how immigrants were absorbed into U.S. society (1979). Historically, earning a high school diploma was enough to secure stable employment, and benefit from job stability and financial security. As Gonzales states, "Given the restructuring of today's economy into a bifurcated labor market, and the elimination of well paying manufacturing jobs, having a mere high school education is 
now not enough" (2008: p. 36). Along with changes in our economy, contemporary immigrants are facing harsher immigration policies as well as contexts of reception (Rumbaut 1997).

As argued by Stepick and Stepick, the segmented assimilation model simply means that, "not all children of immigrants assimilate or integrate in the same fashion or achieve the same outcomes" (2012: p. 18). This theory suggests that structural and sociocultural factors explain why immigrant groups fare differently (Portes and Rumbaut 2001; Stepick and Stepick 2012). Undocumented immigrants face the worst possible context of reception into the United States, faced with exclusionary policies, the threat and fear of deportation, and discrimination. Undocumented immigrants have restricted access to higher education, which is the traditional and most effective method of upward mobility. According to the segmented assimilation theory, these obstacles conspire together to relegate undocumented Hispanic/Latino immigrants into the impoverished underclass.

This assimilation model contains passive and sometimes accusatory language, especially concerning "successful" and "unsuccessful" assimilation of immigrants into society. In my personal opinion, this model still uses ethnocentric language, and has a narrow definition of what "successful assimilation" is. This model is also criticized for being "overly pessimistic" (Alba and Nee 2003). Alba and Nee (2003) argue that segmented assimilation theory neglects the theory of immigrant optimism, and that eventual incorporation into American society is likely. Stepick and Stepick provide a thorough analysis of segmented assimilation theory which effectively refutes much of the 
theory's criticisms (2012). Stepick and Stepick explore the history and contributing theories of segmented assimilation theory, in which "the origins of the concept" are traced to "unravel the controversy surrounding it and to show how the concept has evolved...to a more nuanced, complex framework that is a work in progress influenced by a growing body of empirical knowledge" (2012: p. 7). Their work addresses the controversies of this theory in turn, and manages to successfully counter many of the theory's criticisms. Echoing Stepick and Stepick, this model is still undergoing refinement and adjustments; it may be that this model will fall short in addressing the identities and realities articulated by this study's undocumented participants. Regardless, the components of this theory are the best suited to address this research at this time; no other theory provides such inclusiveness of terms and consideration of multiple identities, assimilation factors, and formulas ascribed to the children of immigrants (Stepick and Stepick 2012: p. 18). 


\section{Chapter VI: Research Design}

\section{Purpose Statement}

This in-depth interview research project explores the impact of Hispanic/Latino students' perceptions of legal status barriers on their educational attainment experiences. The study examines the different opportunities and obstacles present in access to postsecondary education for undocumented Hispanic/Latino students residing in the United States. This study focuses on the time period just after high school graduation, a critical stage in these students' lives, when undocumented status is particularly consequential. This research describes how obstacles and opportunities identified affect the educational attainment experiences of undocumented Hispanic/Latino youth, and how factors work to influence students' goals, dreams, and realities.

\section{Significance}

This thesis contributes to knowledge development, policy, and practice. Research findings contribute to knowledge development by identifying factors that facilitate and impede successful socioeconomic integration of undocumented Hispanic/Latinos, particularly in terms of the educational pathways (un)available for undocumented students. The results also inform practice in regards to the best ways to interact and support undocumented Hispanic/Latino students. The research provides pertinent information for future political debates concerning immigration reform, which has the potential to transform policy. This study informs policy in regards to the success of Hispanic/Latino students. More broadly, this research contributes to the broadening of academic literature on the topic of educational attainment and immigrants. This study 
identifies key factors that block educational access and articulates the consequences of denying post-secondary education to undocumented Hispanic/Latino students in their own words, particularly the effects this lack of access has on their occupational opportunities and aspirations. This contribution to literature provides an additional resource for describing the broader social inequalities present in denying these students post-secondary education, and the consequence not only in these students' lives, but the consequence on society as a whole.

\section{Research Questions}

A key aspect of this research is how undocumented Hispanic/Latino students understand the role that documentation status plays in their educational attainment experiences. This research sought to understand the processes involved in undocumented Hispanic/Latino students pursuing post-secondary education, choosing an occupational field, and developing goals to achieve a specific career or position. There are several specific questions addressed. These are:

1. What are the educational goals of undocumented Hispanic/Latino youth in this study?

2. How do undocumented Hispanic/Latino youth feel about their educational progress?

3. What factors influence whether or not undocumented Hispanic/Latino youth pursue post-secondary education? 
4. How do undocumented Hispanic/Latino youth understand the choices that are available to them if they are unable to access post-secondary education in the United States?

"Educational attainment experiences" can be broken down into different categories or types of experience. Undocumented Hispanic/Latino students' educational goals, progress, and navigation of post-secondary education differ from one another in subtle but significant ways. The research questions for this study address the different aspects of "educational attainment experiences".

Knowledge about students' perception of their educational progress sheds light on their educational attainment experiences; it illuminates important factors associated with their individual educational experiences. Interactions with teachers, school authorities, family, peers, and other authority figures are described in connecting personal interpretations and emotional responses to specific events in participants' lives that they feel helped or hindered their educational progress. Students' assessments of their educational progress identified important areas or periods where students felt vulnerable, unmotivated, or unprepared versus stable, motivated and prepared.

Knowing how undocumented Hispanic/Latino youth identify and understand the factors that facilitate or impede their navigation of post-secondary education further informs educators and researchers alike. This study identifies additional factors for educators, researchers, and our communities that hinder or facilitate the educational navigation and success of undocumented students. Delineating the factors associated with undocumented Hispanic/Latino students' educational navigation increases 
awareness of how these students understand their educational experiences and prospects.

Clearly, these components constitute a vital part of their educational attainment experiences and life.

Due to the exploratory nature of this study, the initial research questions only touched the surface, and in order to address different themes, beliefs and attitudes, and to gain depth to the study, the research was approached in an iterative fashion. The interview questions were refined and updated throughout the data collection phase. Changes were made to the order of questions, as well as question wording. Certain questions were also removed and replaced with more relevant and provocative questions.

\section{Project Design}

Sixteen undocumented Hispanic/Latino students of traditional college age, (1825), 9 male and 7 female, were interviewed. All interviewees were selected through a snowball sample orchestrated through personal contacts, and contacts from OLI programs. One additional character interview was conducted with a previous OLI program director.

\section{Participants and Sampling Frame}

The snowball sampling strategy was used to find participants from this population for the study. Multiple personal contacts in this population, as well as OLI program directors, who knew of additional students that fit the criteria for participation, were utilized. These contacts connected me to additional eligible contacts in order to build the sample size. The proposed sample size was fifteen to twenty, and sixteen participants were interviewed. Participants were of traditional college-age (18-25), undocumented 


\begin{tabular}{|c|c|c|c|c|c|}
\hline Pseudonym & Sex & Age & Birthplace & $\begin{array}{l}\text { Migration } \\
\text { Year and Age }\end{array}$ & $\begin{array}{l}\text { Reason for } \\
\text { Migration }\end{array}$ \\
\hline Adan & $\mathrm{M}$ & 20 & Guerrero, Mexico & $1999 ; 7$ & $\begin{array}{l}\text { Saw economic } \\
\text { crisis coming }\end{array}$ \\
\hline Andrea & $\bar{F}$ & 26 & Vera Cruz, Mexico & $1996 ; 8$ & $\begin{array}{l}\text { Father had work } \\
\text { visa in US }\end{array}$ \\
\hline Armand & $\mathrm{M}$ & 23 & Guerrero, Mexico & $1999 ; 9$ & $\begin{array}{l}\text { The "American } \\
\text { Dream" }\end{array}$ \\
\hline Arturo & $\mathrm{M}$ & 19 & Mexico City, Mexico & $2004 ; 10$ & $\begin{array}{l}\text { Parents divorced } \\
\text { and Father moved } \\
\text { to US }\end{array}$ \\
\hline Blanca & $\mathrm{F}$ & 20 & Mexico City, Mexico & $1999 ; 7$ & $\begin{array}{l}\text { Corrupt and } \\
\text { morally } \\
\text { compromising } \\
\text { politics } \\
\end{array}$ \\
\hline Brenda & $\bar{F}$ & 20 & Michoacán, Mexico & $2002 ; 10$ & $\begin{array}{l}\text { Father had stable } \\
\text { work in US }\end{array}$ \\
\hline Carla & F & 18 & Guerrero, Mexico & $2003 ; 8$ & $\begin{array}{l}\text { Increased gang } \\
\text { violence, no stable } \\
\text { work }\end{array}$ \\
\hline Diego & M & 19 & Jalisco, Mexico & $1996 ; 3$ & $\begin{array}{l}\text { Work and money } \\
\text { better in US }\end{array}$ \\
\hline Enrique & M & 21 & Sinaloa, Mexico & $2001 ; 9$ & $\begin{array}{l}\text { Hard to maintain } \\
\text { stability in } \\
\text { Mexico }\end{array}$ \\
\hline Juan & $\mathrm{M}$ & 21 & Guerrero, Mexico & $1994 ; 2$ & $\begin{array}{l}\text { Economically } \\
\text { better in US }\end{array}$ \\
\hline Julio & $\mathrm{M}$ & 18 & Mexico City, Mexico & $2005 ; 11$ & $\begin{array}{l}\text { Drug cartel made } \\
\text { Mexico dangerous }\end{array}$ \\
\hline Luz & $\mathrm{F}$ & 23 & Mexico City, Mexico & $2005 ; 15$ & $\begin{array}{l}\text { US considered } \\
\text { safe }\end{array}$ \\
\hline Manuel & $\mathrm{M}$ & 22 & Jalisco, Mexico & $1995 ; 4$ & $\begin{array}{l}\text { Better work and } \\
\text { educational } \\
\text { opportunities }\end{array}$ \\
\hline Maria & $\mathrm{M}$ & 18 & Morelos, Mexico & $2006 ; 11$ & $\begin{array}{l}\text { Work and } \\
\text { educational } \\
\text { opportunities }\end{array}$ \\
\hline Paola & $\bar{F}$ & 19 & Guatemala City, Guatemala & $2006 ; 12$ & Financial disaster \\
\hline Roberto & $\mathrm{M}$ & 18 & Morelos, Mexico & $1998 ; 4$ & $\begin{array}{l}\text { Educational } \\
\text { opportunities for } \\
\text { family }\end{array}$ \\
\hline
\end{tabular}


Hispanic/Latino students, who arrived in the United States before the age of. All participants attended U.S. primary and secondary educational institutions.

There were no preferences regarding where students immigrated from, within Latin America, or how they obtained undocumented status; the only preference was for students who grew up in the United States, and who grew up as undocumented students, whether knowledgeable of their status or not.

Four undocumented Hispanic/Latino males of traditional college-age were personal relations of mine. All four volunteered to be interviewed, and were most useful in building this study's sample size. These four participants (Enrique, Juan, Manuel and Roberto), provided access to other undocumented Hispanic/Latino students who fit the study's criteria. The privacy and anonymity of these participants has been maintained by first obtaining verbal consent from the participants themselves, and then by replacing participant names with pseudonyms in all thesis write-ups. All identifying information that was necessary to obtain is in secure location which meets with IRB approval.

\section{Data Methods}

Interviews

The interviews were between 30 and 120 minutes in length, with the average interview taking 51 minutes to complete. All interviews were tape recorded, and took place at the participant's location of choice. The interview questions covered the following topics:

- Immigration Experiences

- Family Role 
- Educational Experiences

- Educational Attitudes

- Educational Interests

- Aspirations: Personal, Educational, and Occupational

The interest of this research was how documentation status affects these students' education following high school. These interviews were meant to draw out students' understandings of how their documentation status affects their educational attainment. The questions followed a logical pattern in order to build on one another and illuminate specific themes or responses.

\section{Data Analysis}

The interviews were transcribed as they were completed, in order to allow analysis and data collection to occur in concert and better inform one another. This assisted in time management, and also allowed for the refinement of the interview guide. Upon reviewing the first couple of interviews, my mentor and I were able to identify certain questions and probes that were eliciting rich data and those that needed to be edited or taken out completely. We also found that reordering some of the questions was necessary. For example, following the first couple of interviews, I discovered that questions regarding my participants' interactions with documented and citizen youth were irrelevant, and were consequently removed from the questionnaire. My mentor also suggested removing questions regarding participants' and their media usage that had been included in the original questionnaire, as these questions seemed out of place and elicited 
very little relevant responses from participants. All interviews were tape-recorded, and their data has been stored in a secure location.

Themes from the literature review, the research questions and related codes from Abrego's research were used to code the transcripts. These theory-generated codes include immigration experiences of students, immigration experiences of parent(s), family role, family expectations, positive educational experiences, negative educational experiences, educational attitude in (primary education, secondary education), and aspirations (prior to and after learning of documentation status). These main themes allowed me to pull clusters of related information from the transcripts to be broken into manageable parts and the main themes identified. 


\section{Chapter V: Findings}

I identify five major themes from the participants' discussion of their experiences: disillusionment, immigrant optimism, opportunities, resources, and expectations. I address these five major themes from my research, and review the four research questions this research sought to answer. The first major finding is what I define as disillusionment, a period or stage of depression, unhappiness, fear, and loss of motivation which was described by every participant interviewed. This finding includes experiences as described by the participants of their disillusionment, and explores how participants perceived their period of disillusionment affected their goals. The second major finding is immigrant optimism, which was an unexpected outcome given my experience with the topic. Here I describe the expectations and perceptions participants had that exhibit immigrant optimism.

The third finding is how these students view and define their opportunities. Participants' expectations and perceptions are explored, broken down into three main opportunities identified by the participants. The fourth finding I address is the type and effectiveness of different resources undocumented students need and use. The three resources consistently mentioned are family, mentors, and significant others. The significance of these supports is also addressed. The fifth finding discusses expectations for these participants; expectations their families have for them, expectations these participants have for themselves, and the expectations these participants feel society, as a whole, has for them. This chapter concludes with a revisit of the four research questions. 
The information gathered from this research that addresses each respective research question is discussed in order to further familiarize the reader with this study's results.

\section{Disillusionment}

The first major finding was not a surprise. What I did find surprising was the pervasiveness of this experience. All interview participants either directly addressed or made a reference to a stage or period in their life when they felt depressed, sad, angry, envious, or shocked, and many described a loss of motivation to succeed in school, obtain a license, apply for college, or search for work. I refer to this period as the period or stage of disillusionment, where the participant learned more about their limitations, challenges, and potential threats as an undocumented immigrant. This period or stage does not appear to be an indefinite period, but seems to depend on the person encountering the stage and their personality and support system.

When interviewed, participants responded to the question, "What was your initial reaction to this information?"

"I was jealous of my friends for something as simple as working at Subway..."-Diego

"It still took me two months or so before I was fully able to grasp what they were saying, that I was undocumented, I didn't have legal status...It made me feel a little more pessimistic about what the possibility was for me to go to college, or even get a good job...I never blamed them. I knew it was not their intention to put me in that situation, but I was just a little more pessimistic about where I would end up." -Manuel

"You feel very deprived, limited. It's frustrating because you envy and you get jealous of so many things that are just, the simple fact of students starting to drive that are in your grade and you can't do that. I felt this way the remainder of my high school years...I always had the hope that maybe something will happen. Yeah, it sucked a lot, because...it did suck a lot though, you feel like it's not fair because you see other students who maybe they didn't try as hard getting something you wanted and you can't get." -Blanca 
“Angry. And sad that they didn't understand, that they claim to be, to understand just about anything and then when they get thrown something like that they refuse to listen to any argument...Yes. I still feel that way." -Brenda

"The license were taken out so I couldn't get my driver's permit, and that made me feel horrible because everyone in my class was getting their permit and I couldn't. I did feel different because I couldn't get a job, I couldn't get my driver's license. I did feel like I was discriminated. And then, once before I got my social security, my work permit? I had an interview at Panda Express and I didn't have a social security number back then. I felt really bad when they asked me, that they used E-verify, and that if I was sure I was legal. I felt horrible. I did used to feel embarrassed of my status and ashamed." -Maria

“At the beginning, I was really sad and depressed, and I didn't want to do anything, I didn't want to go forward. And I think, because of that I messed up a lot in my school, work, everything. I was just, I felt lost. But then I got really angry because then I started learning why they said we were undocumented, like how they treated us for being undocumented." -Luz

"It wasn't fair" -Juan

Following that interview question, students were asked, "Did you perceive any complications with your goals or future?"

"Universities and colleges were never on my mind, it was always, just finish high school and see what happens next...Even if I have a degree, what good is it if I don't have papers?" -Roberto

"I thought...that I wasn't going to go anywhere with my education because without a Social Security Number, without being legal, you can't really do anything. I kept thinking, maybe I should just go back to Mexico." -Enrique

"It was hard. It was hard to know that senior trip I wasn't going to be able to go. All these kids were making plans about what they were going to do and what school they were going to go to. It was hard learning that I wasn't going to be able to do the same...Probably when I could only take three [credits] per term and I figured it was going to take me thirty years to finish college because I could only take three credits per term. So I think that's when it became more real, like as an adult. Like, never going to finish college at this pace." - Andrea

"I realized that most of my goals that I had were going to just take longer, and then, I just kinda, I guess my life kinda just went down from there. Because I realized that I wouldn't 
have it as easy as everyone else, but at the same time I wouldn't be able to do a lot of things that all my friends could. And then just kind of closed all these dreams that I had, like travel...it just kinda said like, no, you can't do that...My first years in high school I still thought, 'Hey, maybe if I get good grades I can get good scholarships or something,' and then I realized I still wouldn't be able to apply for them, like my senior and junior year. 'Oh well, I'll just got to PCC anyway.'... I just felt like, what's the point?" -Carla

Each participant made some reference to a period of disillusionment, but the eleven excerpts above were selected for their more defined and clear reference to how this disillusionment affected the participant and how they felt. The quotes mentioned were in response to the interview questions concerning Documentation Status Experience. More specifically, "How old were you when you learned you were undocumented? How did you find out/who informed you?" "What was your initial reaction to this information?" "Did you perceive any complications with your goals or future?" As mentioned above, every student made reference to having some period of disillusionment. The most common feelings or responses expressed were: Depression (sense of sadness, hopelessness, or direct reference to being depressed), Anger (frustration, or direct reference to being angry), Shock (numbness, denial followed by sudden and sharp realization, or denial followed by being overwhelmed with a specific emotion, and one participant described feeling neutral, as though the information had not affected them). Others described feelings of jealousy, envy, pessimism, and a sense of being left out.

\section{Immigrant Optimism}

The second major finding that came out of this research was the unmistakable "immigrant optimism." The "immigrant optimism" hypothesis was not incorporated into 
my research until I was in the middle of my data collection, having conducted eight interviews with undocumented Hispanic/Latinos of traditional college age. Prior to data collection, I had assumed that I would hear similar responses to those described above with the period of disillusionment.

I had expected that the sixteen interviews I conducted for my research would result in similar, if not identical, messages; feelings of hopelessness, depression, loss of motivation, anger, frustration, confusion, and anxiety. Instead, I heard baffling optimism in the face of trials. At first I attributed this to the recent political program, Deferred Action for Childhood Arrivals (DACA), to which many of my interviewees had applied for and received temporary visas. I also rationalized that in light of such groundbreaking strides forward for undocumented immigrants, it could not be altogether surprising that I would hear such optimism from these students, especially as tuition equity is slowly being passed in a greater number of states, and political energy is being focused on comprehensive immigration reform.

Then I interviewed students who had not received DACA and who were students with no visas, no papers, were working multiple jobs to support their family, and had no current path to citizenship. I also interviewed students who were taking breaks from school, or who had put off school for the time being because they could not afford it. These interviews held the same level of optimism as my first four interviews, which had presented me with the unexpected optimism. The following responses were collected from interview questions, "What do you enjoy the most about living in the US?", "How do you think your life would have been different had you stayed in your home country?", 
"What are the advantages and disadvantages of being an undocumented immigrant?",

"How has being undocumented affected your schooling experience?", "If a reform is not

passed and the situation remains the same, or worsens, what do you see for your future?", and "Do you have any other comments or things you would like to share?"

"I love this country, I love the opportunities it has for people... when it comes to education, it probably would have been harder, to get educated [in Mexico] because there's not many opportunities as here. Here I am able to travel and I am able to do stuff with the school, like school sponsored trips...School there is very competitive, especially the good schools...Also, once you graduate there, I mean, people talk about here not having jobs, I mean, over there they have no jobs, college graduates...A lot of people are coming here...My parents are making more money here working fast food." -Adan

"People talk about being grateful for what they have; I think my past experiences have allowed me to be grateful for what I have, for what I'm doing now. I mean, when I was young, I saw poverty, like, big time poverty down in Mexico City, so you know, it's kind of being grateful for the little stuff I do have here, and also being an immigrant trying to go to school, trying to get an education, I think it allows me to appreciate the system here, that we have in this country. And like, not take advantage of the stuff we do get here... and also the stuff I don't have, like the citizenship? It will give me like, more, appreciate more when I do get my citizenship." -Adan

“There is ways to be creative. You know, like 'I can't do that,' what are some ways around it or how can I make it work? I think it made me think outside the box a lot more." -Diego

"I think I would have been a screw-up, honestly. Even here I was close to being a screwup, that's why I say it. There's motivation that I had here that I wouldn't have, have had over there. I mean, there would be a lot of excuses if I was in Mexico to be a screw-up and that I could justify it with. But here there are a lot of things that are keeping me going through...slow...I know PSU has opportunities, and things are changing with the government, so maybe eventually we'll get opportunities to get papers and to go into another college. But right now it's just looking out for opportunities. Volunteering, you know, getting your name out there and having people know you ad getting those contacts right now." -Roberto

"I appreciate education a lot more. I see it as a once chance thing. A lot of people say, you know, 'Whatever, you know, I'll do this later, I'll take this class later on,' I say I only have one chance to get this right." -Roberto 
"You have more opportunities here than you would in Mexico, as in you get to learn the second language...go to school, because I know there's possibilities of going to school." - Juan

"I enjoy that I, the feeling, that I feel safe, when I'm around. Also, education, I love it. I mean, yeah, you have to work for it because, I mean, as undocumented students you don't get any type of financial aid or anything. But, I enjoy school. I enjoy, I guess the possibility to, I guess you can... and I mean obviously it depends on each person, but I mean, as long as you work hard for what you want you can get as much as you can accomplish for what you want. Over here, you can make it." -Luz

"I mean, and I think the reason why like, I think, like, I'll be pregnant [if I had stayed in Mexico] and I'll be like, I'll have a family, because there is just, there is a limit over there, in Mexico. There is a limit where you can dream about, but then you realize that it's not really, it's not going to happen. But you can dream about a family and that can happen. Aspirations are really low, I think, [in Mexico]." -Luz

"You know, to be honest, an advantage to being undocumented in the United States, because in Mexico if you're undocumented, it's way difficult. It's harder for someone to be undocumented in Mexico than it is in here. Like, we deal really bad with undocumented people in Mexico... [Julio interjects: "Like Guatemalans."] ...yeah, like Guatemalans and Hondurans, we kill them...Even though we are undocumented here we're still have some type of right, some type of rights and some type of laws that protects us. I mean, yeah, it's bad, but compared to other...[Julio: "Countries."], we're good here." -Luz

"I found ways to work and get tuition waivers, so, to pay for my tuition. There was one point where I had, like, three jobs to pay for school? Which is good because I now, I don't owe any money. But it was really hard." -Andrea

"It's important to know that it's not impossible. I feel like a lot of kids, or a lot of students feel like it's a lot of pressure to go to school, and it's hard because there's no money, but I feel like, you can find ways to go to school. You can, there's always something that you can do. And I feel like it's not impossible, and I feel like people need to know that." -Andrea

"It is not impossible to reach my goal. But, it will be harder than it is now. Nothing's impossible." -Paola

Immigrant optimism was identified by analyzing responses and comparing thoughts, feelings and beliefs about obstacles and challenges with negative or unsure 
content to responses with positive and confident content, illustrating a clearly optimistic response.

\section{Limited Opportunities}

The third major finding I discuss from this research is how these students perceive and define their opportunities. Despite the limitations and obstacles these students face, every student I interviewed had a vision or goal for their future, and more than that, they had a plan to achieve that goal. Students perceive any program, legal act or law, and action that allow them to improve their condition or the condition of their family, and community as an opportunity. There were many opportunities defined by these undocumented students, but the main two, the two opportunities addressed and defined by the majority of participants, are DACA and education. The participants from this research describe DACA as a developing opportunity for achieving their goals at this time. DACA provides these students a valid work visa, allowing greater access to better paying, and more stable work, which provides better financial capital for college credits. It also provides a two-year reprieve from deportation. The following are in response to the Interview Questions, "What do you know about DACA?", and "How does or will DACA affect you?"

"DACA is an improvement. We are getting there step by step." -Enrique

“"'For right now, I'm deferred. It allows me to stay here and allows me to better pay for my education." -Diego

"Without DACA, it was so hard to find work. It made life very difficult, and affected how I saw myself. DACA also has made me feel safer, like, it is not possible to be deported. I feel more like I belong." -Maria 
"If it remains the same I still see myself working and going to college and hopefully getting into graphic design and advertising, but of course, renewing the DACA every two years. DACA makes this bearable; it allows me the opportunity to work." -Carla

"I feel like if it remains the same with me having Deferred Action, I would constantly renew my Deferred Action permit...And I think I could be able to have a stable life, maybe not totally secured, but a stable life. I feel like I would be able to, in the future, always have a job." -Blanca

Education is the opportunity these students have most in common with each other, with every student interviewed being either currently enrolled in college credits, planning on enrolling in college credits in the upcoming Fall and Winter terms, or having completed college credits and planning on returning when they are able to afford the costs associated with a college education. Students perceive education as their greatest opportunity, associating education with upward mobility, self-sustaining career paths, and stability. Undocumented students perceive education to be an opportunity for the same reasons documented students and U.S. students consider education to be an opportunity; because we know that the more education a person has, the higher their financial capital is, the better their health, and the greater their access to careers that are capable of providing for a family above the poverty level. An added advantage to education for undocumented students is the opportunity to learn more about the system, community resources, and leadership opportunities to assist them in their current struggles, and to educate them for future involvement to serve their families and community.

The following are in response to the interview questions, "How do you feel about education?", and "How has being undocumented affected your schooling experience? How has it affected your views on education?" 
"When I go talk to undocumented students in other high schools, I tell them, 'You know what, face the truth,' you know? Like, 'You are going to have a lot of obstacles ahead and education is going to be your best bet in going forward, you know?' Get your education, do good in high school, get those scholarships, get those positions where they ask you, 'Have you had any leadership experience? Yeah, OK, you're hired.' Things like ASPCC, you know?"-Adan

"Education is that knowledge, I think education is important, because, I think, like, the more you know the more opportunities you do have, and then you have more access to opportunities...I think you can never have too much knowledge...Learning something that, you know, that you can have, and no matter how much they strip you down they cannot take that knowledge away from you." -Diego

"I'm really, really grateful for education just because it opens your eyes to a lot of things... once you get to higher education, then you really appreciate that knowledge that you get." -Roberto

"With the type of careers that are coming out now, a college degree is essential, when maybe fifty years ago, forty years ago, if you had a high school degree, I mean, that's all oyu needed. If you had a college degree it would definitely get you the big paying jobs, hopefully, but all you needed was a high school degree. But right now, I'd say a college degree is definitely critical. So if you want to get a job where you're going to be stable, and not so easily laid off, you need college education." -Manuel

"Education is really important, it will open doors to succeed in life." -Arturo

"Education is very important, and my Dad always said that, you know, education is the one thing that no one can take away from you, so, the more education you have, the more prepared you are in life, and no one can take that from you. So that's the one thing that's yours. So for me, education is important because, I feel like, you're more prepared, you're just more prepared for jobs, you're just more prepared in life. If we do have kids one day, I want them to be proud of us for going to school." -Andrea

"Education is important to me because I, my parents, they didn't really have the opportunity to go to school and had to work at a young age and I feel like if I have the opportunity and the ability of going to school then I should otherwise it would just be a waste and it would be throwing it in my parents face that I'm not going to school just like they didn't, even though I have the opportunity and resources to do so. It would be disrespectful and ungrateful not to get education when my parents have sacrificed so much just for me to do this." -Brenda 
"Because of my documentation status, I value education more and cherish everything I get from it." -Brenda

"Like you said, it's going to make me rich, possibly [laughter], and if I'm thinking about having a family, I think about if I have a higher education, I'll have a higher income and a better chance for them to continue into college without many difficulties." -Maria

"I don't want to be cleaning houses like my mom, so I want to have, like, a better job, something that gives me financial stability instead of going month by month. And just to help out my mom, I guess, later on when she's older. And just to have a better life for my family, as well." -Carla

"I don't want to give up on education. I have a pretty big family, especially from my mom's side, and I can see the difference between going to college and not going to college...I can tell the difference and I know what kind of lifestyle I want for me and for my future family." -Paola

"Education is important because I need it in order to get to, a better future for myself and my family." -Blanca

"Education, college wise, it is way ahead of everything else. You get to take action because it is preparing you for your life, and it's not something to take for granted or playing around. You need to take it seriously." -Enrique

"I have always thought that education was the key to progressing, and I think my hard background, you know, the obstacles I've faced, really gave me that light, you know, if you want to better yourself, do something with your life. If you have a passion, do it, follow a career, get an education, you know. You don't want to just be working at, like, Jack in the Box, and that be your life. I mean, there are some people that have to, like my mom, you know, that's her life. She wakes up, goes to work, comes home. That's her life. Work, work, work, work. And it's not like she's working somewhere glamorous, she works in a fast food restaurant. And when I see students who voluntarily, say like, 'I'm not going to go to school, I'm just going to do that, work in fast food, you know?' I'm just like, you're wasting your life, you're wasting a good opportunity you have." -Adan

"I have cousins, who are U.S. citizens, and I am always like, how lazy can you be? They don't try in school. They have all these opportunities just handed to them, and I am over here struggling and afraid of being deported, but still working really hard to do well in school and everything. I swear it has made me stronger. I see how people who live here in the U.S. don't really appreciate what they have, and it motivates me to do better. I work twice as hard to be better than average so that people can see, that, you know, I belong." -Julio 
"I remember in high school how everyone was so worried about college applications because of GPA and money, and I was like, I have great GPA. I worked my ass off. And I was in student leadership, and in sports, I did it all. I knew it wouldn't make a difference, but in a way, not being documented made me want to prove myself. I still am. Now in college, I study, and work so I can pay for classes, and I have an internship, and have found scholarships, and all without papers. I learned who to go to for advice, for information, for help, and for connections."

-Manuel

\section{Importance of Social Support}

Here I discuss key sources of support for undocumented Hispanic/Latino youth, and their importance. The three key sources are identified in order of importance and frequency. First, family (parents, siblings, extended family), next, mentors (counselors, advisors, teachers, authority figures), and lastly, significant others (spouse, boyfriend, girlfriend).

The majority of participants incorporated their family into the interview, crediting parents and siblings with providing the support and motivation they needed to pursue their goals. Family was most often referred to as a social support when asked about their parent's expectations for them, their greatest strengths in continuing their education, how they are motivated, and who they turn to for information and answers. Students went into great detail as to how their parents had sacrificed for them to have a better life here in the United States, and how their family continues to support them in every way they can, providing residence, meals, money, transportation, emotional support, and information when needed. Many students mentioned younger siblings as their motivation for success, and the majority of participants described their desire to succeed similarly to the way that Brenda described in her interview, "My parents want me to have better than they have. A 
better future, a better job, a better education, a better everything. They left Mexico

because they knew I could never have better if they stayed, and now they work two jobs each to provide for my siblings and I in the hopes that we can one day have everything they never did. I do this for them because I know they have provided me the opportunity for a better life, and I will not waste what they have worked so hard for."

The following responses identifying the different types of resources were made in response to the Interview question, "'What has been your greatest strength or support in continuing your education?", "How have you overcome these obstacles to education?", and "How do you motivate yourself?"

"My family helps with my school costs...I live at home, rent free, get rides, they help pay for certain school needs." -Enrique

"My dad. My dad is the one that has always pushed me I feel like. And he has no legal status and he's been working and given us everything possible. Um, we never had more than we needed. Like, we never had cool toys, we never had, like, a nice car, or brand new computer. But we always had what we needed. We always had food, we always had shelter, if we needed books we would get them. Anything that we needed for school we would always get. It didn't matter if we spent two-hundred dollars on school supplies, as long as it was for school, my dad always provided that. I feel like he is the one who has always motivated me to go to school, and I feel like I want to continue going to school because I want to make their experience worth it. I want to make what they went through to get us to this country worth it." -Andrea

"A reminder that my parents did not have this opportunity, and I want this. My parents are my motivation." -Brenda

My mom is helping me pay for school, too. And of course I live with her, and she supports and encourages me." -Carla

Uh, definitely my mom. And my older brother. Because they were the ones who held my family together when my dad wasn't here." -Blanca 
"I am lucky. My sister went to college before me, and she is undocumented too, so she knows all the ins and outs of registration, and how to choose classes, setting up advising appointment, and how to pay for school. Everything. She knows everything and now she helps me. It is almost like having, you know... a genie." -Julio

"I was scared and really confused when I first tried going to college, and if it wasn't for my mom and dad always drilling me about how important education is, I would have quit. But they gave me strength. They believed in me so much. Now, here I am, about to graduate with my bachelor's." -Luz

"My family and the people around me who motivate me and positively influence me."Juan

Mentors were mentioned fairly consistently throughout interviews, though not as frequently, and were never discussed as in-depth, as family. Mentors were most often high school teachers and counselors that had taken time and provided resources outside of school for students. Participants relayed memories of when their school counselor had taken the time to find colleges, scholarships, jobs, and programs that accepted or targeted undocumented Hispanic/Latino students, and even spent time going over applications and information in order to be of the best help. Other mentors were college instructors or leadership directors that participants had taken a course with or had volunteered under. These mentors were able to provide better information and present relevant options to students, as they had a wider knowledge base and more experience.

The students who identified their resource as a high school or college level mentor mentioned that these mentors were useful when students had questions regarding school and documentation related questions, and were especially invaluable when it came to questions regarding DACA and the process of applying. Mentors provided up-to date, and detailed information for students, provided time and provided connections to other 
resources designed to assist undocumented students, such as scholarships or school positions tailored for migrant families, undocumented students, and students on school visas. Mentors also provided a safe place to share fears and doubts regarding school, work, and the future.

"It took me a while to figure out that those people were there to help you out and they didn't care that you were undocumented or not. Some of them didn't even know, you know? They didn't even know what undocumented was... So by my senior year I found that it was a mixture of educators and my counselor. She really helped out. And sports. They all kept me out of trouble, kept me off the streets." -Adan

"I had a counselor, and he was definitely, kind of had me turn all that, he definitely had me look on the positive side of things, and he helped guide me. He told me, like, 'Hey, you need to do well in school and you need to keep going on because, what if things happen to change. What if there is a law or something that comes up.' He gave me an example, 'If you do good, you know, if you graduate and things go good, you know, you'll be set. But if you, compared to someone who isn't doing good in school, doesn't graduate, and then some big old action happens, you know, who is going to look better, you or him?' Kind of made me look at it positive, motivated me to keep pushing forward." -Diego

"I think it was a teacher. He was a really strict teacher, but he also expected a lot from me and that helped me."-Maria

Significant others were only mentioned by three participants, one of whom was married. Significant others were considered a source of emotional and physical support. The significant others to the three participants are all documented and/or U.S. citizens, allowing participants an offset to the crushing burden of financial need. Andrea, who considers her husband her greatest resource, explained that being married increased her financial capital, as her husband works and is also eligible for FAFSA, loans, and most scholarships, so that any income could and did go to her school expenses. A quick note; the three participants who responded with significant other as their greatest resource still 
have considerable assistance and/or contact with family (i.e., live with parents, eat with family, work with family, receive some form of assistance from family). Even Armand who lives with his American girlfriend, financially contributes to his family, and financially provides for his own education, mentioned his family and their support.

"I think it's definitely my family. They've always supported me. That includes my girlfriend. They've always supported me. Giving me moral and physical motivation. Like those days where I would study and not make food and my girlfriend or my mom would make food for me. Those little things that help you out a lot." -Armand

Other social supports mentioned were church groups, school programs, sports, and leadership groups. These supports were not grouped together due to their lack of compatibility, frequency and depth of description. Only one participant mentioned his involvement in a church youth group as a source of support, and school programs and sports were vaguely described by participants, allowing the researcher to assume that these social supports were not as influential as those of family, mentors, and significant others. However, these other social supports, also considered community social supports, are significant to the health, security and community ties of undocumented immigrants. While they may have played a minor role in the participants' lives, they are still influential in the process and progress of these students' educational experiences.

\section{Expectations}

This section describes the different expectations undocumented Hispanic/Latino students feel they face from family, society, and themselves. Here participants describe the expectations their parents and siblings have for them, as both students and family members, and the expectations they feel others have for them, most often referring to 
political and community attitudes. Last, these participants explain what they expect from themselves, as students, as undocumented immigrants, as workers, and as children to unauthorized immigrants.

Based on substantial statistical research regarding Hispanic/Latinos and education, the Hispanic/Latino population has remained the least educated of all minority groups in the United States, falling behind the African American population, the nonHispanic White population, and far behind the Asian population (Gándara 2010). In the past, critics have attributed the achievement gap to a number of factors, such as language deficiency, cultural conflicts, and have also blamed the parents, claiming that parents of Hispanic/Latino students fail to encourage or stress the importance of education to their children.

On the contrary, recent research has shown that immigrant parents, documented and undocumented, are fierce advocates of education. Hispanic/Latino parents consistently encourage their children to complete high school and continue on to college. In the case of undocumented Hispanic/Latino immigrants, the major factor driving immigrant parents to enter the United States illegally is the opportunity for their children to have better educational outcomes. Participants shared their impressions of what their parents and families' expect from them in response to the interview questions, "What job/education level do your parents want for you?", "What expectations does your family have of you?", and "How do you feel about their expectations?"

"My parents have always expected for me to finish high school and go to college. Even though I am undocumented, they wanted me to keep going. They know that to succeed 
here, I need college education, and that has always been the message. They expect me to contribute to the family as well, because we all need to contribute to make it, so I help out with bills when I can. It is just that school is so expensive for me." -Paola

"Our parents have always wanted the best for us. I think that what they want most is for us to have better than they have. They expect us to go to school and get a good job so we can take care of ourselves and our family, and not have to worry about bills and food. They don't want us to become doctors or lawyers, or anything like that. They just want us to have better. I know that that means college." -Diego

"My dad has always pushed me towards education. He has always said that education is the only thing worth risking everything for. He knows he does not have all the answers himself, but that has never stopped him from expecting me to do my best and to earn a college degree." -Andrea

"My little brother and sister were always looking up to me. They expected me to help them when they got to school because I guess they thought I would have all the answers. To be honest, I did learn a lot in my first years of school, so I have been able to help them." -Armand

"I always felt like my brothers were expecting a lot from me. Like, I knew my parents had all these expectations, even though they didn't always understand what it took to complete a lot of the goals I had, but I was surprised when I realized my brothers had expectations too. I was the first person in my family to go to college, so I was the first to encounter all the legal obstacles, and enrollment obstacles, and how to pay for everything. My brothers expected a lot from me because they knew they would have to face all the same challenges, and they wanted me to help them." -Luz

Participants also felt that their school peers had expectations of them, although the impressions they got from their peers were regularly negative. The following are participants responses to the interview questions, "What are the disadvantages of being undocumented?", "What had the most negative impact on your high school experience?", "How did you relate to your U.S. born peers?", and "Have you ever experienced discrimination, or different treatment in high School or college?"

"Nothing. They act like I am nothing because I am brown, and they are white, and because I speak Spanish, and those who knew I was undocumented loved making fun of me. They expect me to fail. They always have. They expected me to not make it through high school, they expected me to be some sort of, gangster. I'm not. And I am so close to my bachelors now, I just want to shove it in their faces." -Armand

"I always felt like no one at school thought I would make much of myself. I got teased, and bullied, just because I was different. I think no one thought I would graduate. When I 
watch the news or try to follow the debate over immigration, no one really says, 'Hey, they are all criminals who have ten kids and push drugs, so let's deport 'em all,' but with what they do say, like drug cartel uses the border, and bringing up that we don't do well in school, and we abuse social programs, and what they don't say, that is the message I get. No one expects much of any of us. So sometimes, I don't expect much of myself.' Arturo

"I had a friend, well; I thought he was a friend. But in high school, my senior year, he started making fun of me because I'm undocumented. He told me, in front of the whole class, that I was useless, and I would never get far cause I didn't have papers. He started teasing me, saying I couldn't even drive, so how could I ever work. I pretended it was a joke, but really, I started believing him. I wondered how I could ever do what I needed to if I couldn't even drive? The class thought it was so funny, all these white kids not caring that I was just as smart as they are. It made me feel like everybody was out to get me. All the white people anyways." -Juan

Lastly, participants described what they expect from themselves, as students, and as family members.

"I never really thought about it before. I guess I expect to succeed. I expect to finish school, with a good GPA, and get a job. I want to stay close to my mom, and help out so she doesn't have to work as hard. I don't think I expect a lot of myself. I expect to just be, normal." -Carla

"I expect a lot of myself. I want to get a PhD in biochemistry, and do research. I want to live in the US, and help take care of my parents because they deserve so much better than what they have. It is weird. I expect so much from myself, even though so many expect nothing of me." -Brenda

"I know what I want, and I guess, it is sort of what I expect to achieve. I have always wanted to serve in the military. I still want to. I want to serve the US, and it is just too bad that they won't let me. I don't know. I guess I expect to finish school and go into law enforcement then. I mean, with my background, who would be better to serve people like me in [City name]? So, I guess, I expect to serve anyways. I expect to help people, and I still want to enjoy life. I am working so hard for what I want, I think that at some point, I should be allowed to enjoy my life." -Enrique

"To prove everyone wrong. I am going to finish school, with the degree I always said I would have, and then I am going to work in my field, and I will have proved everybody wrong. That is what I expect from myself." -Luz 
"To finish what I started. I expect to prove to myself that I can do this. I work so hard, and I know I am smart. I just need to keep pushing myself, and I will succeed. That is what I expect from myself, to finish school and prove that I can." -Paola

One particular experience stuck out regarding the expectations others have of participants. Manuel took a different approach to this question and explained how he felt that America itself had an expectation of him, to dismiss his Mexican heritage and fully embrace mainstream American culture. Immigrant students find it difficult to balance these two value systems, and most often embrace American culture and values as they feel American values are what will help them succeed in American culture. Manuel explained that in high school, he made the conscious decision to act American in order to succeed. At the time, Manuel was enrolled in ESL classes, which he realized were inadequate, and did not reflect his abilities as a bi-lingual and bi-cultural student. Manuel told his parents that he wanted to be placed in the mainstream classes for his grade. His parents, unfamiliar with the ESL curriculum in his school, advised him to remain in ESL, where they were sure the school had placed him correctly.

Manuel recognized that the ESL program at his school did not provide the information and content necessary for him to progress in his studies at the same rate and level of his American peers. He told his parents that the ESL classes would make it difficult for him to graduate, and that the school had not taken the time to interact with Manuel and place him properly. Reluctantly, Manuel's parents agreed to contest the schools placement, and Manuel was enrolled in regular classes.

At first, the material was difficult, but Manuel adapted quickly, and learned that he needed to act like an American student in order to succeed, and even excel. Manuel 
recalled feeling out of place as he "acted" out his part. He focused on speaking English at school, participated in school sports, and was involved in student leadership. He maintained this separation of self well into college, before he realized how draining it had been to disconnect himself from his culture and other value system. He realized he needed both value systems in order to be whole, and worked on re-familiarizing himself with the cultural values he had tried to distance himself from.

In conclusion, I identify five major themes from my research, each an important factor in understanding the perceptions of undocumented Hispanic/Latino youth and their educational attainment experiences. The first theme is a period of disillusionment which every participant mentioned experiencing, relating to the revelation that they were undocumented, or to the reality of being undocumented. Participants expressed feelings of depression, anger, shock, and a loss of motivation. The second theme, immigrant optimism, describes the ability of these undocumented students to remain optimistic in the face of great trials. The third major theme was opportunities. Two opportunities were discussed, DACA and education. The fourth theme was the importance of social support. The social supports discussed were family, mentors, and significant others. These supports provided physical, emotional, and mental support to participants. The fifth and final theme discussed was expectations. Participants expressed the expectations they felt their family and society had for them, both as students and members (of the family, or as members of society). Participants also described the expectations they had for themselves as students. 
Following the discussion of the five major themes, I review the four research questions for this research. In reviewing the research questions, I find that the educational goals of the participants are to earn a college degree in the field of their interest and use the degree to work in their desired occupation. On that note, participants are frustrated and often feel discouraged by the prolonged process of earning their education, a result of financial difficulties and restricted work and school options.

Three factors which influence undocumented student's pursuit of higher education are identified: family, a specific personality trait, and outside support. Lastly, participants consider their educational access intertwined with their ability to live and work in the United States safely. If participants are unable to access or complete their educational goals, they perceive they have three options; first, working jobs they qualify for with DACA and getting involved in immigration policy change. Second, returning to their country of origin, or moving to another country that will allow them access to education. The third option is marriage to a U.S. citizen. 


\section{Chapter VI: Conclusion}

In order to draw out novel information, the major themes of this research are associated with previously conducted research. In many cases, it is not surprising that the themes of this study serve to strengthen and promote ideas and arguments found in the literature. My intentions, however, are to identify where the themes of this research provide new or under researched information in order to validate this study's contribution to sociology. Despite the limitations I recognize for this research, the major themes identified have significant implications for education, policies that impact immigrant groups, as well as sociology. While my focus for this research was on the educational consequences undocumented Hispanic/Latino youth encounter, further research is needed to understand: the circumstances that lead to unauthorized immigration; the period of disillusionment and its effects on undocumented Hispanic/Latino youth; the long-term consequences of denying an increasingly large population access to affordable education, stable occupations, and other various rights and privileges.

\section{Period of Disillusionment}

Because the majority of my participants were never required to prove their documentation status as children, the reality of their status was unknown. Many were unaware that they did not have papers, and had always believed they were American citizens like their peers. It was in the process of applying for a job, filling out college admission forms, applying for financial aid, and trying to schedule a driving test to receive a license that these participants became aware of their documentation status. For those who did not know they were undocumented, this knowledge was a shock. For those 
who were somewhat familiar with their documentation status, this re-affirmation of their position in the United States was a rude awakening. Because they had spent so many years unaffected by their status, they had come to believe they did not have limitations on their futures'.

As students near the end of their secondary education, they also near the end of their legal protections. This "sudden discovery" comes with "immediate and severe consequences" as participants' goals are diverted and re-assessed (Gonzales 2008: 191). As evident from the participant's responses in my Findings chapter, it takes participants time to come to grips with their new reality. It takes time to understand what being undocumented means, and if it is a temporary or permanent situation, and what it means for everyday routines. This period of discovery is rife with emotion. Reactions to the knowledge of being undocumented vary from participant to participant, but one thing that remained constant was that this period was not infinite. Whether a participant reacted with initial shock, anger, confusion, numbness, depression, jealousy, or pessimism, the period that this initial emotion occurred for was just that, a period of time. While there is no set time period for how long a participant experienced this period of disillusionment, it can be assumed that how a participant discovers their documentation status, and how the information is handled, directly correlates to how disruptive the knowledge is.

Because my research is not representative, I cannot confidently claim that this period of disillusionment is significant in influencing the choices and actions of undocumented Hispanic/Latino youth. I can, however, safely say that it is a significant period in these students' lives. This period is when participants compare how they 
thought their futures would progress to how they now feel stuck because the things they thought they could do are restricted. I consider this to be disillusionment; a time when participants are exposed to the reality of their situations, and are forced to identify limitations and barriers to dreams and goals. This period of disillusionment is most disruptive because of when it occurs; at a time when participants are transitioning into adulthood, taking on more responsibilities, considering their futures, thinking about marriage and children. At this time the choices participants make have important consequences. One wrong choice can have drastic consequences, physically, emotionally, and legally.

As Gonzales (2008) states, "While the decisions participants make during this particular period do not always determine their education and labor market outcomes in the long run, they certainly shape their early trajectories and impact their well-being and overall outlook" (p. 189). Participant responses both concur with Gonzales' observation, and present something new. Based on participant responses, the period of disillusionment most notably impacts student motivation, student emotional health, and student mental health. However, this period is highly influenced by the way students learn of their status, and the communication between parents and children. Based on responses from participants, open communication and honesty alleviate much of the anxiety and fear associated with the period of disillusionment.

Participants responded better to parents explaining why they had limitations, what those limitations are, and how to operate in spite of these limitations. Participants with parents who avoided this type of discussion, and had little to no information for their 
children experienced higher anxiety and fear, and a marked loss of motivation for completing their education. This is important for the parents of undocumented students to understand. Parents need to have accurate information for their children, and reliable sources of information if there are questions the parents cannot answer. By providing information or reliable sources of further information, students can better navigate this period of disillusionment, and maintain mental and emotional stability.

This period of disillusionment is arguably the single most influential period for undocumented Hispanic/Latinos. Goals are re-configured, students endure a period of emotional and mental upheaval, rules and limitations must be identified and learned, and students' sense of safety and security has been violated. In order to minimize the effects of this period, parents and other authority figures involved in the lives of these students have a lot of responsibility. As mentioned above, parents need to be open and honest with their children. Parents also need to educate themselves in order to better serve their children. Knowing who to trust in the school system is important, having an advocate can help, and discussing a child's status with them before they are faced with a rite of passage will help to strengthen undocumented Hispanic/Latino students. Remaining positive and realistic also aid in minimizing the period of disillusionment in these students lives, and can prevent the negative assimilation of these youth.

\section{Immigrant Optimism}

I mention in the previous chapter when introducing the finding of "immigrant optimism" that it was a surprising factor. I had not expected such amazing levels of resiliency, and as this resiliency became consistent in the interviews conducted, I had to 
broaden my literature review. The students I interviewed have maintained an impressive optimism. These students seem to occupy two mindsets simultaneously; one mind optimistic, the other overly aware of the barriers they will face. I want to stress that during the interviews students expressed distress and often a lack of motivation for college, citing financial struggles, family expectations, the need to work, and the fear of deportation as just a few of the obstacles to higher education. This was what I expected. What surprised me was the optimism these students maintained even as they expressed concern for their futures. One second they would be stressing the need for financial aid and how without it, they cannot complete their education, and the next, they are saying they have great hope for the future, and are always focusing on the future.

Others have expressed their dedication to education and their optimistic outlook on life as a tribute to their parents, and the sacrifices their parents made so that they could have a better life. Still others mentioned the current political atmosphere as a reason to be optimistic, these being the students who had received work visas through the DACA program. It seems that these students are able to simultaneously recognize barriers and obstacles to their education, and formulate solutions to overcome these barriers.

Originally I was concerned that the optimism these students maintained would prevent them from developing realistic and/or accomplishable goals in regard to education and future careers. I am now convinced that this optimism is one of the greater motivators in these students' lives. I have no doubt that these students are acutely aware of the barriers they currently face, and will face in the future, but they manage to thrive in many ways, and even come up with creative ways to overcome trials. As Diego 
describes, "An advantage to being undocumented is we find creative ways to get around things. We have to think outside the box to find ways to solve problems, and I think that gives us an edge."

Critics of immigrant optimism argue that as impressive as this resiliency is, the strategies these students devise to allow them security in the face of insurmountable odds only allow a micro level of this population to subsist in the face of such a harsh political climate. These critics argue that while undocumented students have learned to live in an environment with scarce resources and numerous legal restrictions, they ultimately have little power over the macro level institutions that govern their limitations. Based on the responses I have heard from this research, I have to disagree. While I am not overly optimistic about the opportunities these students have in this current political climate, I feel that this immigrant optimism has the potential to be more impactful than critics give it credit for.

What this research contributes is a more focused view of how immigrant optimism affects these students' lives. Optimism keeps students focused on the future, where they see a world of potential. The family and larger cultural values these students draw from maintains and perpetuates this immigrant optimism, and I have no doubt that this is what these students will need to succeed, not just in their education, but in their efforts to reform immigration at the national level. This resiliency is what is needed to change the political climate. I argue that immigrant optimism is capable of allowing these students to succeed and to make the changes necessary to improve immigration and education. From what I have heard in this research, immigrant optimism allows these 
students to survive and to plan for the future, and if we want to benefit from this optimism, we need to improve educational access for these students and make their lives more visible. These are the students who are going to reform immigration, even if it is one step at a time.

\section{Limited Opportunities}

In the previous chapter I identify policy changes, such as DACA, and education, as the most prevalent opportunities identified by participants. Because DACA was passed in 2012 , there is little to no research to add to this discussion. This makes this study a unique contribution as it is one of the first to describe how DACA influences behavior and educational attainment. There are pros and cons that have been identified by various researchers as well as the participants themselves. I use these observations to augment my discussion on DACA. I follow up with a closer look at the dedication participants have to education, and the factors that foster this drive.

The advantages to DACA are a 2-year work permit, the opportunity to obtain a drivers license (varies by state), the ability to obtain auto insurance (varies by state), and the increased possibility of obtaining a social security number (varies by state and would be valid as long as DACA is current). Participants also feel that DACA provides a greater sense of stability and security, and gives them hope for future policies. There is also the opportunity to travel in-country, and abroad (Ranchod Law Group 2013).

Disadvantages include restrictions on travel; no guarantee on reentry into the United States; criteria for DACA denies eligibility for most parents, older siblings, and older extended family. The criteria for DACA also denies eligibility to individuals with 
a criminal record. Other disadvantages are this policy's subjection to presidential and political changes, a lack of consensus on the deportation reprieve, and the finality of the USCIS's decision.

Participants made it clear that DACA was not what they had hoped it would be, explaining that it feels very temporary. Adan was very forward with his disappointment of DACA's limited scope. However, it has allowed greater security for participants and their families. It has also improved their ability to find and apply for better paying jobs, increasing their sense of financial stability for the time being. For now, they accept and take advantage of DACA's benefits, but they are not satisfied. There is an expectation for further action to build off of DACA in order to open a pathway to citizenship.

Education was the second opportunity identified. Education was discussed by each participant interviewed, and plays a large role in the lives of these students. The topic of education and undocumented Hispanic/Latino immigrants can be broken down into three areas; first, the values and meanings undocumented families bring with them from their country of origin; second, immigrant optimism and its effects on education; and third, the expectation of pursuing education.

Valdés (1996) recognized that immigrant families brought with them a different set of values and meanings from their country of origin, and these values are often incompatible with the values found in American society. Valdés (1996) argued that for immigrant families, education and schooling do not have the same meaning in the United States. For many undocumented Hispanic/Latino families, the values held by the parents of students are "filial loyalty, reciprocity, conformity to social conventions, and 
maintaining social linkages" (Valdés 1996: 172). These parents still highly value education, and support their children in attending and completing their primary and secondary education, but the traditions and values held by these families are in direct conflict with American values and educational traditions. For example, Valdés (1996) shares the change parents experience as new arrivals in the United States, where they learn that high school graduation is considered essential to living life. But families had never imagined that choices would have to be made between responsibility to the family, and the ambitions of the children. Parents had assumed that their children would be able to earn credentials and succeed in school while managing to "put family first" (Valdés 1996: 173).

Immigrant parents did not understand that in America, encouraging children to pursue education and believing in education involved much more than making sure their children attended school. In fact, as Valdés (1996) explains, parents in her study spoke positively about education, but their everyday practices and activities would be considered unsupportive by mainstream standards. I encountered this in my study as well. Participants explained that their parents encouraged them to graduate high school, and pursue higher education, but that they did not seem to understand the time, energy, and prioritization required to succeed in the American educational system.

As Valdés (1996) and Valenzuela (1999) argue, immigrant parents are not familiar with American education and often provide conflicting advice and observations. Luz best expressed this idea when she shared the interactions she had with her parents in her first year of college. Luz explained that her parents had been unfamiliar with the costs 
of a college education, and were often critical of the time she spent apart from the family. Luz had to limit the time she spent with family because she was busy working to afford her school credits, and needed time to study in order to pass her classes. After her first year, Luz showed her parents how much school had cost, and explained to them that she had needed time and space to study. Luz recalls that her parents did not bother her about school after that, and explained that her parents were able to be more supportive and familiar with college requirements for her brother when he started college.

It is difficult for the children of immigrant families to navigate two different value systems, especially when each value system continues to be emphasized by different authorities in their lives. Immigrant parents want their children to grow up with the same notions of "reciprocity, responsibility and respect that have been part of their families for generations" (Valdés 1996: 172). Teachers and leaders in the United States expect students to dedicate themselves to learning, and assign different meanings to the values of respect and responsibility. Students in America are expected to be more independent and competitive. There are also extra-curricular school activities that are emphasized in order to make students "well-rounded" and more appealing on future college applications.

Manuel's experience described in the Findings chapter is not uncommon, although his reconciliation is. It is not uncommon for immigrant students to choose the dominant cultural values over their parent's value system. Much like Manuel, students realize that in order to succeed in the United States they need to adopt American behaviors and values. Unlike Manuel, however, many students fail to reconnect with their 
culture and remain disconnected. This can lead to complications with family, and has a profound effect on how they view themselves.

The second area related to undocumented Hispanic/Latino youth and their dedication to education is the relationship between social capital and schooling. Valenzuela (1999) refers to social capital as, "the social ties that connect students to each other, as well as the levels of resources (such as academic skills and knowledge) that characterize their friendship groups" (p. 116). According to Valenzuela (1999), aggressively school-oriented students, like the participants from my study, exist because they possess greater social capital, which Valenzuela argues is demonstrably linked to their schooling experiences in Mexico.

As argued by Valenzuela (1999), "Immigrants invoke these prior experiences through their comparative or dual frame of reference, which not only motivates their achievement but also mitigates their critique of U.S. schooling" (p. 117). Much like immigrant optimism, this dual frame of reference allows participants to "evaluate their circumstances in the United States through the lens of their prior schooling...experiences in Mexico" (Valenzuela 1999: 117). This social capital, a combination of immigrant optimism and what Valenzuela identifies as empeño, or diligence, is manifested as a sense of loyalty and purpose, "that undergirds both their higher achievement and their pro-school ethos (Valenzuela 117)."

In short, the 1 and 1.5 generations possess higher social capital in comparison to second and third generation Hispanic/Latinos, because they have a dual frame of reference (Valenzuela 1999). The 1 and 1.5 generations maintain strong ties to their 
culture throughout much of their primary and secondary schooling, which allows increased confidence, navigational skills, and awareness. This social capital maintains a healthy persistence, and if fostered during high school, can continue to serve students into their college years.

The fostering of this social capital is important, because as Valenzuela argues, if students possessing abundant social capital face tremendous odds in their efforts to achieve, how much poorer are the chances of success for students with little or no social capital (p.140). If students are not allowed to maintain and build their social capital, they will not be able to fully benefit from it, and this can influence their decision or their ability to pursue higher education. The participants from my study all seem to have benefited from this social capital, owing to the support of family, friends, teachers, counselors and other mentors. So in spite of various obstacles participants met in their secondary schooling years, the fostering of their social capital allowed them to overcome and maintain a pro-education attitude.

The third area is the expectation to pursue education. The majority of participants described the expectations their parents had of them, and education was always a priority. Although parents did not always seem to understand how much education was needed, and the different kinds of degrees and skills, participants learned quickly the importance of education, and took their parents encouragement. Many participants also explained that they had been instructed by their parents to do better and have a better life than they did, and participants often view education as a possibility to better their lives. Many participants see the abusive work relationships their parents have, and they want to avoid 
that kind of a future. This is what their parents expect as well, so parents are quick to support their children in their educational endeavors as long as there is the potential for improvement to their situation.

As I tried to make clear in the Participant Table, of the sixteen interview participants, four had two parents with "some college", completed in Mexico, and three participants were emphatic that their mother's had received "technical training", which they referred to as a type of college, also completed in Mexico. The fathers of these three participants, however, were reported to have a sixth-grade education level. The remaining participants possess education levels that surpass those of their parents. Even the participants with parents possessing "some college", were unable to explain how much college their parents had, or if they ever completed any form of degree. Participants were also vague when reporting that their parents had a high school education; most participants volunteered that their parents had attended high school, but failed to mention whether or not a parent had graduated from high school.

Valdés (1996) performed great research on the interaction of parents and children and American education. Immigrant parents hold positive views about education (Valdés 1996). Despite the marginal lack of education for parents in Valdés'study, parents of immigrant children ( 1 and 1.5 generations) recognize the importance of American schooling for their children (1996:151). For many of the parents in Valdés'study, education was a sensitive subject, owing, as Valdés perceived, to both the parents lack of continued education, and the reality that in several families, children had gone beyond the educational levels of their parents (1996: 151). According to the participants in my study, 
ten participants had gone beyond the educational level of both parents, and another two had gone beyond the educational level of one or both of their parents. While I did not interact with the parents of my participants in any way, judging from the language spoken by participants parents, (predominantly Spanish), and from their occupations (mostly low wage occupations), the parents of my participants are very similar to those in Valdés' study (1996).

The parents in Valdés' study express similar views and expectations about education as the views and expectations my participants report their parents as having (1996). Valdés (1996) argues:

In different ways, parents in the study demonstrated that they valued schooling. They were aware of their own limited opportunities, and they wanted their children to have more. Even in the face of the many competing demands on the family system, children's schooling was still considered important. (P.155)

Participants in my study reported similar practices and expressions from their parents as the parents in Valdés' study (1996). Participants in my study with younger siblings were often admonished to set the example for younger siblings; parents expect older siblings to learn and succeed in the American school system and to provide guidance to younger siblings when the time comes for them to navigate school. In Valdés' study, the daughter of one participant dropped out of high school to get married, and the mother lamented her choices because she knew that in America, people who did not finish high school had fewer choices (1996). The mother was also worried that her younger children would follow in their older sibling's footsteps and abandon their education. 


\begin{tabular}{|c|c|c|c|c|}
\hline \multicolumn{5}{|c|}{ Table 3: Parent's Education } \\
\hline Pseudonym & Sex & Age & Mother's Education & Father's Education \\
\hline Adan & $\mathrm{M}$ & 20 & Some College & Some College \\
\hline Andrea & $\mathrm{F}$ & 26 & High School \& Technical Training & $6^{\text {th }}$ Grade \\
\hline Armand & $\mathrm{M}$ & 23 & Some College & Some College \\
\hline Arturo & $\mathrm{M}$ & 19 & $6^{\text {th }}$ Grade & $6^{\text {th }}$ Grade \\
\hline Blanca & $\mathrm{F}$ & 20 & Some College & Some College \\
\hline Brenda & $\mathrm{F}$ & 20 & $6^{\text {th }}$ Grade & $2^{\text {nd }}$ grade \\
\hline Carla & $\mathrm{F}$ & 18 & $7^{\text {th }}$ Grade & N/A \\
\hline Diego & $\mathrm{M}$ & 19 & $7^{\text {th }}$ Grade & High School \\
\hline Enrique & $\mathrm{M}$ & 21 & High School & High School \\
\hline Juan & $\mathrm{M}$ & 21 & $6^{\text {th }}$ Grade & $6^{\text {th }}$ Grade \\
\hline Julio & $\mathrm{M}$ & 18 & Some College and technical training & $6^{\text {th }}$ Grade \\
\hline Luz & $\mathrm{F}$ & 23 & Some College and technical training & $6^{\text {th }}$ Grade \\
\hline Manuel & $\mathrm{M}$ & 22 & High School & $6^{\text {th }}$ Grade \\
\hline Maria & $\bar{F}$ & 18 & $5^{\text {th }}$ Grade & $8^{\text {th }}$ Grade \\
\hline Paola & $\mathrm{F}$ & 19 & Some College & Some College \\
\hline Roberto & $\mathrm{M}$ & 18 & $9^{\text {th }}$ Grade & $9^{\text {th }}$ grade \\
\hline
\end{tabular}

Similarly, participants in my study reported that their parents often reminded them that education allowed them greater opportunities, and that not completing high school would offer fewer choices for work and safety. Participants in my study also reported that while their parents had the best of intentions, they were not well equipped to help with the material being taught in American schools. Participants in my study also reported 
many confusions and misunderstandings their parents had about school and the programs offered. Valdés (1996) recognized that:

Commitment and interest in education, however, were not enough to make up for the parents' lack of familiarity with U.S. institutions...There was much confusion about programs, requirement and grading. There was much misinformation within the family collective experience about what worked and what did not. (P.155)

Luz best illustrates the gap between commitment to education, and understanding the requirements and systems in the U.S. schooling institution. In her interview, she reported that her parents were dedicated to her completing her high school education, but were not able to provide a lot of hands on support. Her parents were also supportive of her continuing her education and pursuing a college degree, but Luz reported that they had been surprised; to her parents, a high school degree was considered the pinnacle of education. They had not considered that in America, a college education would be the minimum required to be eligible and competitive in the work force.

My research findings for opportunities, DACA and education, provide a more focused attempt of understanding the role that documentation status plays in the lives of the 1.5 generation. Undoubtedly, undocumented immigrants recognize education as the best method of achieving upward mobility. Parents of undocumented students value education, and students have an appreciation for the opportunity of education. Nevertheless, from what participants have shared, immigrants, or first generation immigrants, do not understand the role education plays in U.S. society. Too many immigrants follow the "American way", believing they can "pull themselves up by their bootstraps". For the majority of undocumented immigrants, work is the only way to 
succeed in the United States. They recognize the importance of education, but are not able to conceptualize how it affects their success in American culture.

Undocumented students of the 1.5 generation understand better the role and importance education plays, and are more motivated to complete high school, and continue their education in order to earn a degree that will provide greater occupational stability. This break in knowledge between the first and the 1.5 generations is cause for miscommunication between children and their parents. A greater observation is that parents misunderstanding of education often results in their reluctance or dismissal of programs or opportunities for them to improve their educational levels.

\section{Importance of Social Support}

According to Perez et al., “...undocumented Hispanic/Latino youth draw on specific personal, family, and school resources to circumvent the effects of various stressors as well as social and institutional barriers to become academically successful" (2009: 28). Participants identified three main resources in my study, family, mentors and significant others. The data gathered from my research regarding resources strongly supports Perez et al.'s argument for resources and their significance in the lives of undocumented Hispanic/Latino youth (2009). While the main resources identified by participants in my research were family and mentors, a select few participants made references to outside resources such as a community program, a church group, or school programs that they participated in. I did not include these outside resources in my discussion on resources as a finding because only a few participants mentioned outside resources, and the information about outside resources was vague. I would like to 
recognize some of the outside resources here, if only to further impress the significance and variety of resources available to undocumented Hispanic/Latino youth.

School leadership and school sports were seen as great resources, both in high school, and in college. Adan, Blanca, Armand, Luz, Manuel, and Roberto all made references to school leadership positions and school sports. Adan reported in his interview that sports had been one of things to "keep [him] off the streets". These six participants all held high school leadership positions, and continued in leadership when they entered college. Adan, Armand, Manuel and Roberto still participate in sport activities, such as campus soccer clubs, and volunteer to help with local community soccer teams. Andrea made reference to a Leadership institute that she participated in during high school. She reported the Leadership institute as being useful and inspirational to her in her high school years.

Three participants also referred to a high school program called Early College, where students are able to attend college classes that are financed through the school. Arturo, Paola, and Maria participated in the Early College program, and reported feeling grateful for the opportunity to take college courses that were paid for by their school. These three participants also felt that this program was partly to credit for their successful graduation, as they had not felt welcome or able to blend in at their respective high schools. One other participant, Juan, had attended a type of alternative high school, called Oregon Youth ChalleNGe Program (OYCP), part of the National Guard youth outreach. He graduated from this program, what he called high school boot camp, instead of attending and graduating from traditional high school. Juan reported that OYCP was what 
he had needed in his life, and shared that his experience with OYCP continues to provide opportunities for him.

These resources proved to increase resilience in participants, opening doors and increasing connections and networking opportunities. Participants in my study regarded these resources as important in their ability and decision to complete a high school education and pursue a college education. These outside resources, along with the previously identified resources of family, mentors, and significant others, further support Perez et al.'s claim that undocumented Hispanic/Latino students are able to possess high levels of resiliency when there are protective factors (or resources) to counteract obstacles (2009). While Perez et al. (2009), in my opinion, underestimated the role of family as a protective factor, my research suggests that family is one of the most significant protective factors for undocumented Hispanic/Latino youth. Based on responses given in my interviews with participants, I argue that family (parents, siblings, extended family, and children) provides the greatest source of support and motivation for undocumented Hispanic/Latino students. Family was reported to have physical (shelter, food, transportation), emotional, and spiritual influence for the participants in my research, which successfully counterbalanced any suggested deficits caused by family living.

\section{Review of Research Questions}

"What are the educational goals of undocumented Hispanic/Latino youth in this study?" 
Based on participant responses in the Opportunities section of this paper, the educational goals of the undocumented Hispanic/Latino students in this study are identical to typical U.S. high school graduates, namely, to attend college and earn a college degree. As evidenced in the Participant Table accompanying this thesis, the participants in this study have a wide array of occupational goals and interests. No two participants share the same occupational goal. For example, multiple participants express an interest in criminal justice, but with different careers in mind. One participant wants to join law enforcement, another wants to specialize and become a member of SWAT, while still another wants create programs to serve women offenders of color. Two participants are currently working towards degrees in engineering, with one participant focusing on civil engineering, and the other on environmental engineering. One participant is determined to earn her PhD in Biochemistry, while another wants to become a pharmacist.

The career aspirations of these participants vary dramatically, but the foundation for any of their future careers is the same: education. Of the sixteen different career aspirations expressed in the interviews, the one thing they all have in common is the need for a college degree. Of the sixteen participants, only three, Julio, Arturo, and Andrea need two-year associate degrees or certificates for automotive repair, family business and paralegal studies. Six participants require a bachelor's degree as the minimum requirement for the career of their choice, among these criminal justice, graphic design and public relations. Five participants require a Masters degree in order to enter or be competitive in their field, including engineering, international studies, business and/or 


\begin{tabular}{|c|c|c|c|c|}
\hline Pseudonym & $\begin{array}{l}\text { College } \\
\text { Type }\end{array}$ & Career Interests & $\begin{array}{l}\text { Degree } \\
\text { Minimum }\end{array}$ & $\begin{array}{l}\text { Greatest } \\
\text { Obstacle }\end{array}$ \\
\hline Adan & $\begin{array}{l}\text { Community } \\
\text { College }\end{array}$ & $\begin{array}{l}\text { International } \\
\text { Affairs/Business }\end{array}$ & Masters & $\$ \$ \$$ \\
\hline Andrea & $\begin{array}{l}\text { Community } \\
\text { College }\end{array}$ & $\begin{array}{l}\text { Social Work; Legal aid for } \\
\text { minority women }\end{array}$ & $\begin{array}{l}\text { Associates or } \\
\text { Bachelors }\end{array}$ & $\$ \$ \$$ \\
\hline Armand & University & $\begin{array}{l}\text { College or school } \\
\text { administration }\end{array}$ & Masters & $\$ \$ \$$ \\
\hline Arturo & $\begin{array}{l}\text { Community } \\
\text { College }\end{array}$ & $\begin{array}{l}\text { Business; to assist with } \\
\text { family business }\end{array}$ & Associates & $\$ \$ \$$ \\
\hline Blanca & $\begin{array}{l}\text { Community } \\
\text { College }\end{array}$ & $\begin{array}{l}\text { International Studies and } \\
\text { Foreign Language }\end{array}$ & Masters & $\$ \$ \$$ \\
\hline Brenda & University & Biochemistry Research & $\mathrm{PhD}$ & $\$ \$ \$$ \\
\hline Carla & $\begin{array}{l}\text { Community } \\
\text { College }\end{array}$ & $\begin{array}{l}\text { Advertising and Graphic } \\
\text { Design }\end{array}$ & Bachelors & $\$ \$ \$$ \\
\hline Diego & $\begin{array}{l}\text { Community } \\
\text { College }\end{array}$ & Public Relations & $\begin{array}{l}\text { Bachelors or } \\
\text { Masters }\end{array}$ & $\$ \$ \$$ \\
\hline Enrique & $\begin{array}{l}\text { Community } \\
\text { College }\end{array}$ & $\begin{array}{l}\text { Criminal Justice; Law } \\
\text { Enforcement }\end{array}$ & Bachelors & $\$ \$ \$$ \\
\hline Juan & $\begin{array}{l}\text { Community } \\
\text { College }\end{array}$ & $\begin{array}{l}\text { Criminal Justice: Police } \\
\text { Academy; SWAT Team }\end{array}$ & Bachelors & $\$ \$ \$$ \\
\hline Julio & $\begin{array}{l}\text { Community } \\
\text { College }\end{array}$ & $\begin{array}{l}\text { Automotive repair; } \\
\text { Recording and producing } \\
\text { music }\end{array}$ & Associates & $\$ \$ \$$ \\
\hline Luz & University & $\begin{array}{l}\text { Criminal Justice; create } \\
\text { programs for female } \\
\text { offenders of color }\end{array}$ & $\begin{array}{l}\text { Bachelors or } \\
\text { Masters }\end{array}$ & $\$ \$ \$$ \\
\hline Manuel & University & Environmental Engineering & Masters & $\$ \$ \$$ \\
\hline Maria & $\begin{array}{l}\text { Community } \\
\text { College }\end{array}$ & Pharmacist & $\begin{array}{l}\text { Specialized } \\
\text { Degree }\end{array}$ & $\$ \$ \$$ \\
\hline Paola & $\begin{array}{l}\text { Community } \\
\text { College }\end{array}$ & Graphic Design & Bachelors & $\$ \$ \$$ \\
\hline Roberto & $\begin{array}{l}\text { Community } \\
\text { College }\end{array}$ & Civil Engineering & Masters & $\$ \$ \$$ \\
\hline
\end{tabular}


college administration. Maria needs to earn a degree in pharmacy, a five to six year program, and Brenda requires a $\mathrm{PhD}$ in biochemistry to work as a biochemist researcher.

Participants make it clear that they are dedicated to earning college degrees, with multiple participants explaining that they are willing to return to their country of origin, or even apply to schools in other countries in order to achieve their educational goals. The majority of participants credit their parents with motivating them to pursue higher education, and despite the financial difficulties experienced by the participants, as well as limited options geographically, participants remain committed to attaining college degrees. This speaks to the larger issue of immigration, where undocumented immigrants are depicted as uneducated and unmotivated laborers with no goals or visions for a better future. By all accounts, this research suggests the opposite.

\section{“How do undocumented Hispanic/Latino youth feel about their educational progress?”}

Participants regularly expressed anger and frustration when describing their educational progress. Students are upset and intimidated by the financial requirements, because as undocumented immigrants, they are unable to apply for FAFSA, are ineligible for most scholarships, and cannot take out school loans. They also experience work restrictions, or experienced more work restrictions before DACA was approved. However, even with DACA, they are only earning minimum wages, as they have no college education. This results in students taking between three and six credits per term, as this is all they can afford to pay for out of pocket. Andrea sums it up when she shares that she felt like it will take her thirty years to finish school, because she can only take one class at a time. 
Other participants expressed frustration with the prolonged process of earning college degrees. "The biggest obstacle is money. And that is hardest to come by. It is even more upsetting that for students like me, and my sister, who were A students; we could have gotten scholarships for school. And we could be getting FAFSA. We could be so much further along, but instead we are doing leadership so out tuition is paid for, and we are working so we can pay for books, and we work to pay for other costs not covered by our positions. That means we can't be full-time students like we want to be. It is very depressing." -Andrea. This sentiment was expressed repeatedly, with multiple students feeling discouraged by the number of years they would be putting into two and four year degrees.

Another concern was what would happen when they did graduate with their degree. A few participants brought up the concern that even if they did, finally, graduate, unless major changes have been made to immigration, students will be unable to work in many fields, even with DACA. Medical and criminal justice fields will be difficult to break into, even with a degree, and the majority of government positions would also be limited. In conclusion, students feel frustrated and discouraged by their lack of progress, and by the prolonged process of attending college, in spite of DACA.

\section{"What factors influence whether or not undocumented Hispanic/Latino youth pursue post-secondary education?"}

Factors that foster a desire to pursue higher education are family, personality, and outside support. Factors that prohibit or discourage students from pursuing higher 
education are the consequences of not having a social security number, financial costs of education, discrimination, and the threat or fear of deportation.

Family seems to be one of the greatest factors influencing whether or not students pursue higher education. As discussed previously, family represents a major part in these students' lives. Whether it is depending on family for physical support such as shelter, food, transportation, or financial assistance, or emotional support, such as encouragement, advice, support, or motivation, students rely heavily on family involvement. Family involvement also seems to shape how these students perceive education, and their desire to pursue it. Family, specifically parents, influences participants both directly and indirectly.

Directly, parents discuss education with their students, help plan for the future, and provide assistance to continue educational pursuits. Indirectly, parents often serve as a reminder to students why education is so important. Students described seeing how hard their parents work, earning little in return, and many expressed a subtle fear that they would have nothing better than their parents. Participants found that their parents' situation served as a catalyst for educational pursuit. Many explained that not only did their parents want better for them, but participants recognized the sacrifices of their parents in order to provide a better way of life for their children, and participants want to make the sacrifices of their parents worth it. Family is the greatest factor influencing undocumented Hispanic/Latino youth to pursue post-secondary education.

A second factor is personal characteristics of participants. All sixteen participants had some combination of the following characteristics: social competence, problem- 
solving skills, sense of autonomy, high positive expectations, and a sense of direction for the future. These characteristics were exhibited differently in the participants interviewed, but with similar results. These personality characteristics serve as a protective force for undocumented Hispanic/Latino youth, and allow students to retain high levels of resiliency. Resiliency, or immigrant optimism, is significant in influencing undocumented Hispanic/Latino youth to pursue higher education. It allows students to persevere in the face of great trials, and motivates students to work around obstacles. Participants have described great creativity, intelligence, and determination when responding to challenges they face in their pursuit of education. I cannot speak to students who lack the characteristics that these participants have, but I assume that they would find it difficult to persevere when faced with similar obstacles.

A third factor is outside support. This refers to a multitude of opportunities that influence students to pursue higher education, in addition to family support and the above mentioned personality trait. Outside support refers to scholarships students are eligible to apply for and receive, school positions that provide tuition waivers or tuition coverage, support of school or community mentors, such as counselors, teachers, directors, church leaders, and other influential community members. Networking is also very useful to undocumented Hispanic/Latino youth, who need access to tried and true resources. Another form of outside support is policy change. For example, DACA would be considered outside support, and any future policy changes to immigration would also be outside support. 
These forms of outside support help to bolster confidence and make higher education appear more accessible or affordable. Outside support can take many different forms, from the type of advice or support mentors provide, the type of policy change such as DACA which allows students greater employability, to the duration or amount of scholarship funding, or the type of school position a student holds. But all outside support provides additional support to students, support that is needed to motivate students to pursue higher education.

\section{Barriers to Educational Attainment}

The barriers undocumented Hispanic/Latino youth encounter are inextricably linked. These four factors share a complex relationship, where the consequences of one barrier are mirrored or compounded in relation to the consequences of another barrier.

The first factor that discourages undocumented Hispanic/Latino youth from pursuing higher education is the lack of a social security number, or citizenship status. While DACA has provided eligible undocumented Hispanic/Latino youth with a valid work permit, and a type of conditional social security number, the impact is not the same as granting citizenship. Participants are still vulnerable to discrimination and deportation. Participants are still ineligible for federal financial aid, and most state financial aid, and the benefits of DACA in regards to occupational fields are undetermined.

Travel is still restricted and risky; while students can now apply to travel abroad, the application requires a minimum of three months prior to departure, and there is an application fee. The final decision is also participant to discrimination; meaning it is possible that a student may travel abroad with an approved application, but the 
application does not guarantee the participant can return to the United States. Participants with DACA also mention that while their current status may increase their security, it does not allow them the same rights and privileges as U.S. citizens. DACA and other such policies are not permanent solutions. The lack of a social security number and official citizenship status still restricts travel, financial aid, loans, and scholarship eligibility, and continues to limit work and school opportunities.

The second barrier identified by participants is the financial costs of a college education. As the majority of U.S. college students are well aware of, a college education is financially significant, even with financial aid, the option to take out school loans, and eligibility for a variety of scholarships. Undocumented Hispanic/Latino students do not have the luxury of financial aid, are ineligible for federal loans, and are not able to apply for most scholarships. In recent history, undocumented students could be charged out of state tuition as well, which is approximately three times the cost of in-state tuition, all without any financial support. Participants all described the hindering effects of being solely responsible for funding their college education. Prior to the passing of DACA, participants recalled working two to three low-wage jobs in order to be able to afford attending school one class at a time, or part-time at best. DACA has allowed participants to hold better paying positions (minimum wage and better) which has allowed greater financial capital, but participants are still responsible for paying for school out-of-pocket.

Andrea described the prolonged process of earning a degree as the most frustrating part of her educational experience. Other participants expressed similar dissatisfaction. Due to their limited financial opportunities, participants are not often able 
to complete a full term at a time, which extends the time required to earn their degree. A two-year degree can take anywhere from two and a half to four years. A four year degree almost always requires participants to start their college career at a community college, and then transfer to a four-year university, where it can take them another three to four years to complete a four-year degree. This barrier is an ever present weight for students. The costs of education also limit where they can apply.

On a positive note, there have been great strides forward due in part to the creativity and ingenuity of many students. Undocumented students can receive tuition waivers for serving in school leadership positions. Other participants have found internships that accept undocumented students, and others have been able to receive certain scholarships targeted at the migratory Hispanic/Latino population. But this is not enough. This barrier is one of the most effective when it comes to discouraging undocumented Hispanic/Latino youth from pursuing higher education.

The third barrier is discrimination. Discrimination is present in the classroom, on campus, on the street, in the workplace, and in any possible encounters with law enforcement. This barrier is a complex puzzle. There is no doubt that discrimination exists, and these participants are subjected to the experience of being discriminated against based on their ethnicity every day. However, there are different levels of discrimination. Discrimination can be the result of various motivators. Direct or purposeful discrimination is motivated by hate or deep-rooted ideology, and includes violent acts, racial slurs, verbal abuse, and other forms of direct and overt racism or discrimination. Indirect discrimination is motivated by ignorance or fear. This can 
include comments or suggestions that counselors or advisors might make in the belief that they are helping a student, not knowing or not acknowledging that the advice is hurtful or misinformed.

This form of discrimination can also be fueled by media portrayals of "violent" or "criminal" undocumented Hispanic/Latinos, fostering a sense of fear and mistrust of the Hispanic/Latino population as a whole. Discrimination can also be motivated by systemic policies or traditions, also known as institutionalized racism/discrimination. The term institutionalized racism/discrimination was introduced in the 1960's. Sparrow (2009) defines it as "the collective failure of an organization to provide an appropriate and professional service to people because of their color, culture, or ethnic origin" (p. 444).

Institutionalized discrimination goes a step further by targeting a people because of ethnicity, culture or race, and providing barriers or challenges to the success of individuals within the population. Institutionalized racism/discrimination encompasses lack of resources or funds for certain students, different or unprofessional treatment of target populations, hostility, ignorance within the institution (college or university), noncompliance with rules and regulations regarding students or employees of color or other denominations, and the maintenance or creation of exclusionary rules and policies. These forms of discrimination make it difficult for students to trust advisors, instructors/professors, administrators, and other authority figures. It also engenders an atmosphere of hostility and mistrust amongst the student population. 
An example of this is an experience Carla described. Carla was taking a class at a community college, and was doing well. She completed her work, and received A's on all of her work. When final grades came out, Carla had received a B in the class. Confused, she met with the instructor and asked if there had been some mistake. The instructor replied bluntly that no Hispanic had ever passed with an A, and therefore Carla did not deserve an A, so she should be happy with a B. Carla was so shocked by the instructor's attitude and blatant discriminatory practice that she left the meeting quickly. She did not know what she was supposed to do, and decided to accept the B and avoid that specific instructor in the future. As Carla expressed, "Who would have believed me anyways?" Another example was an experience that Andrea encountered, and that actually made local news at the time of the incident. Andrea was serving in the student leadership at her community college where they plan an event called Semana de la Raza (Week of the People), where speakers, cultural displays and other activities are organized to advocate for the Hispanic/Latino population. The event banner used to visually announce the start of Semana de la Raza was vandalized with racial slurs the year that Andrea was part of the leadership group. Andrea recalls "that was the most difficult thing to go through; I had never experienced anything like that before...It was really hard". Such experiences are not uncommon for students of color, and having an undocumented status only increases the probability of being targeted. Discrimination/racism is a constant weight these students are exposed to, and it only serves to magnify their difficulties when interacting and navigating within the educational institution. 
The last barrier identified is the threat or fear of deportation. This threat is twofold. Undocumented Hispanic/Latino students fear deportation for themselves as individuals, and fear the deportation of family and loved ones, as extensions of their lives'. While the participants in this study have all applied and/or received Deferred Action, which promises a two-year reprieve from deportation, the long-standing threat of deportation and lack of consistency with DACA allows deportation to still be used as an effective tool in marginalizing this population. Then there is the threat of deportation of family members, most often parents, older siblings and/or extended family, which are not eligible for DACA. Adan recalls the havoc wreaked by his father's deportation.

Financially the family was in trouble, which required the children to provide financially, in addition to their mothers work. It was also emotionally trying as Adan and his siblings were unsure of when or if they would see their father again, and trying to validate their conflicting emotions with his abrupt departure. Deportation creates chaos for both individuals and their families, ripping apart spouses, siblings, children and parents. The financial burden of deportation is heavy, and it casts an atmosphere of uncertainty and paranoia over this population.

I briefly mentioned that these four barriers are interconnected. In greater detail, consider the first two barriers, lack of citizenship status/social security number and the financial costs of education. Because participants lack citizenship status, the costs of education are greater, due to ineligibility of loans, federal assistance, and scholarships. Likewise, because a college education is so expensive, the consequences of no citizenship status are magnified. Incorporate discrimination, and a corollary pattern emerges. 
Institutionalized racism/discrimination is a long-standing tradition, which has historically affected the financial assistance of minorities regardless of documentation status. So because undocumented Hispanic/Latino students are easier to target (visual ethnicity /race cues), it becomes standard to assume anyone who looks Hispanic/Latino is undocumented, and to create or maintain policies which thwart the efforts of undocumented Hispanic/Latino students in their pursuit of higher education.

Lastly, deportation is a means of controlling the population. By creating a sense of fear and a lack of security, the population remains vulnerable. This has made them less likely to oppose policies and procedures which prey upon their vulnerability, and still manages to minimalize their activism. DACA, while a step forward, is far from the immigration reform this population expected, and needs. There are extensive connections to be made between these four barriers, but the main idea is that each barrier has an effect on each other barrier.

\section{"How do undocumented Hispanic/Latino youth understand the choices available to} them if they are unable to access post-secondary education in the United States?"

Participants did not want to consider a future where they were unable to complete their educational goals, but participants were also realistic. Participants considered the inability to complete or access post-secondary education intertwined with their ability to remain in the United States safely.

As a result, participants considered their options limited. The three main options were: work in order to provide for themselves and their families and increase their involvement in immigration reform efforts; move or return to country of origin; marriage 
to U.S. citizen. Multiple participants were adamant that if the situation in the United States became worse for them and their families, they would be motivated to fight back. Many participants are already involved in advocacy and reform efforts, and others expressed a desire to be more involved. It is quite clear that if push came to shove, students would be more likely to double their efforts to reform immigration, rather than survive in the shadow of injustice.

Other participants said they would be motivated to move. Participants confessed they would consider returning to their country of origin, or moving to another country if it would allow them access to education. This was not meant as an option of moving and not returning. Participants who responded with moving as an option considered this an option because it would allow them to apply for citizenship or valid visas without worrying about being deported. This was only considered an option if educational opportunities were denied; barring that, participants are willing to endure their limitations, relying on their educational progress to benefit them in the future.

Third, three participants considered marriage to a US citizen an option in order to gain citizenship. One participant, Andrea, who was deported to her country of origin, married her long-time American boyfriend and is now finishing the process of becoming a U.S. citizen. It is noteworthy that no participants seemed to consider alternative options: following in their parents footsteps to work low-wage, dead-end jobs; working in family businesses; deciding to participate in illegal activities in order to survive. Critically, participants could have considered all of these possibilities, but did not want to share these ideas, or did not want to consider it could become a possibility. It could also be that 
given participants have not experienced the harsh circumstances theorized, they do not know how they what they would decide to do, and responded with how they hope they would act. However, from what I have heard in participant responses, these students' social capital allows them to see the larger picture; I feel that participants possess greater skills and abilities which would allow them to make these hard decisions without compromising their morals or their goals for their futures.

\section{Contributions}

By situating my research in Northwest Oregon, an area with growing Hispanic/Latino immigration, I am positioned to speak to the sets of undocumented immigrant issues that are unique to this area. Further, in using the qualitative questionnaire designed and employed by Abrego in her research, I am able to confidently build upon a firm foundation and provide a comparison to similar studies conducted in California, by Abrego and Gonzales.

My research was preceded by two years of participation and observation, which allowed me to tailor Abrego's questionnaire to the unique circumstances of my participants, and include more focused questions. The information I have presented in the preceding chapters offers the sociological community a closer look at the circumstances and perspectives of undocumented Hispanic/Latino youth. As such, I am able to contribute to a broader understanding of this population, a significant contribution considering the marginalization of this population and how little we know about undocumented Hispanic/Latino youth. 
This research provides clear implications for undocumented Hispanic/Latino youth and the pursuit of higher education. Such implications include: the need and importance of accurate, up-to-date resources and information; the importance of wellinformed and experienced mentors, counselors and advisors; the role educators play in these students' pursuit of higher education; the need for financial assistance; the consequences of denying a college education to undocumented Hispanic/Latino youth; the effects of documentation status for undocumented Hispanic/Latino youth pursuing higher education.

There are also contributions to knowledge development. Undocumented Hispanic/Latino youth identified, in their words, supports and barriers to higher education. Having these supports and barriers recognized by the students carries greater weight and allows policies to be tailored to the needs of this population. This research is mainly a contribution because the information gathered is in the words of these undocumented Hispanic/Latino youth. It is important to add their voices to the debate as the experiences of undocumented students are often neglected, resulting in a negative view of these students and their families.

This research also contributes to policy. By adding the voices of these students to the debate, they are able to counter the media image of undocumented Hispanic/Latinos as uneducated, criminals, outsiders, and unwilling or unable to assimilate into American society (Vargas and dePyssler 1998). The experiences of the immigrants in this research are those of success; the successful completion of a high school education, and the successful entrance into higher education. These students exemplify the attributes we 
prize in every American citizen; they are patriotic, eager to learn, hard-working, regularly contribute to their communities, provide service, and are respectful of different races, ethnicities, and nationalities.

These participants are the perfect example of why the United States invited immigrants to its shores to begin with; they are shining examples of virtue, sobriety, and industriousness, with a commitment to the American way. This is why their experiences and stories of success are important, and why they are such a significant contribution. Sharing these experiences also illustrates what the United States is missing when it builds policies and legislation designed to restrict immigration and deport undocumented youth.

This research also contributes to practice. The knowledge gained from this thesis is useful in informing authority figures how best to interact and serve this population. Educators, social workers, and community leaders would do well to listen to the voices of these undocumented students. Increasing awareness is another contribution, and allows broader recognition of the supports and barriers facing this population, and can help influence the breakdown of barriers, and the increase of supports. Finally, this research can contribute to broadening the literature on undocumented Hispanic/Latino youth. Again, it is important to include the voices of these students in the literature, in order to gain a better understanding of the reality these immigrants face. It will also help to open a path for future research. Including the affects of limited access to higher education described by these undocumented students adds depth to current literature and can influence future research as well. 
The findings of this research contribute to theory as well. After reviewing and analyzing my findings, I conclude that segmented assimilation theory needs some work. While I still feel it was the best theory for this research, I also agree with Alba and Nee's criticism of the model (2003). Segmented Assimilation theory does not take immigrant optimism into consideration, which is a significant factor in the lives of undocumented Hispanic/Latino youth. Neglecting immigrant optimism causes this model to appear more pessimistic than I feel it should be. If immigrant optimism was included in the model, the theory would be more realistic, a balance between overly optimistic, and pessimistic. This assimilation model has also failed to incorporate a more appropriate definition for assimilation. While scholars seem to use the terms assimilation and acculturation interchangeably, based on the responses of the participants in this study, acculturation should be its own term. Participants are reluctant to assimilate into American culture, not because they reject its values, but because in order to assimilate they are required to abandon their own cultural values, beliefs and identities. Segmented Assimilation needs to recognize what students consider acculturation, or the ability to adopt dominant host society values while maintaining cultural values, histories and languages.

\section{Limitations}

Thesis projects, such as this, suffer from many of the limitations that large research projects do not. The limitations of this study are lack of transferability, small sample size, the sampling frame, and sampling restrictions. The small sample size of this research makes it difficult to claim this study is transferable to undocumented Hispanic/Latino youth in other cities, counties or states. It is possible that this study could 
be transferable to undocumented Hispanic/Latino youth in the Portland Metro area, ages 18-25, as a whole, but it is again difficult to make this claim with such a small sample size. The geographic location also affects transferability, as undocumented Hispanic/Latino youth in other cities and states are exposed to a host of different environmental factors.

The small sample size is another limitation. The sample size for this research needed to be large enough to gather different views and experiences without reaching a saturation point, but small enough to allow the researcher time to interview, analyze, and meet thesis deadlines. Sixteen participants met these criteria, but did not allow for a broad pool of data. A larger sample size with even proportions of male and female participants, and college and non-college participants would have yielded better results.

The sampling frame used was non-random. In order to locate undocumented Hispanic/Latino youth who came to the United States before the age of sixteen, as well as equal numbers of males and females, and to have a manageable sample size, I needed to employ snowball and targeted sampling techniques. As a result, the overall sample is not representative of the entire population.

Another limitation is the sample itself. This sample is limited to traditional college-age Hispanic/Latino students, who personally know a contact used in recruiting, or who participated in an OLI program. This is a very intimate and exclusive group of students. This sample, despite all efforts to the contrary, is devoid of undocumented Hispanic/Latino students who chose not to pursue higher education, or who are not attending or have not attended higher education. While this provides a very clear picture 
of the experiences of undocumented Hispanic/Latino youth who pursue higher education, it is unfortunate that there could not be a comparison made between the two groups.

Trust and honesty with the participants is also considered a limitation as I am considered an outsider. Because of this population's marginalization, and the controversial politics surrounding their existence in the United States, there are potential ethical issues. This study will require the students to trust a stranger with valuable information concerning not only themselves, but their parents, siblings and those they work or interact with. While this information will be kept confidential and will not be used for any other purpose than to explore themes for research, it was a fear that participants would not be comfortable taking this risk. This limitation may be reflected in the small sample size.

Conversely, this research intended to generate a deeper understanding of the complexities documentation status presents in the lives of undocumented Hispanic/Latino youth, and while these limitations provide obstacles to my research, I was able to illustrate the reality that undocumented Hispanic/Latino youth experience.

\section{Future Research}

There is no doubt as to the controversial nature of undocumented Hispanic/Latino youth as a topic. In 2007, three California Community College trustees lost their positions because they supported legislation to make undocumented students eligible to apply for financial aid in California (Supiano 2008). In 2008, North Carolina became the first state to flat out deny the entrance of undocumented students to North Carolina's community college system (Russell 2011). These examples illustrate the condemnation 
great sectors of the population have for undocumented immigrants, as well as a lack of understanding of the extreme circumstances which influence unauthorized migration to the United States. It is my hope that the findings of this thesis help to better illustrate the extreme circumstances and needs of these undocumented Hispanic/Latino youth.

Future research needs to be conducted in order to improve how this population is viewed and addressed in politics, and education. Future research should include a larger number of participants, and should also be able to compare undocumented Hispanic/Latino youth who are pursuing higher education, and undocumented Hispanic/Latino youth who are not and do not plan on pursuing a college education. Research with a larger participant pool can better determine what facilitators and barriers are most important. Future research could also follow undocumented Hispanic/Latino students over a period of years, in order to better capture the transition from high school to college, from young adult to adult, and to better capture the period of disillusionment these students experience.

Future research will also need to focus on Deferred Action for Childhood Arrivals to determine the limitations of the program, and how DACA affects educational attainment experiences. Considering the recent changes in immigration policy and the continued issue of unauthorized migration, there is much need for research. A particularly significant research project would be to explore the relationship between U.S. corporations and the Mexican economy, and the relationship between the U.S. government and Mexican/South American governments. This research would provide a better understanding of how the extreme circumstances which influence unauthorized 
immigration are created, and maintained. Lastly, further research into the legal aspects of being undocumented would be important. Identifying how documentation status revokes certain rights and protections under U.S. law, examining human rights violations on the U.S. -Mexico border and shortcomings within the U.S. deportation system are all important factors when trying to survive in the United States.

The experiences of undocumented Hispanic/Latino youth are not those typically depicted when politicians, the media and other authorities debate immigration. This population of undocumented Hispanic/Latino students is bi-cultural, bi-lingual, and resilient. Juanes is a prime example. Juanes overcome his depression, became an advocate for immigration reform, and is currently completing his college education. However, the fact remains that at one point, this young man with a lifetime of opportunities and experiences ahead considered death to be a better alternative to living as an undocumented Hispanic/Latino in the United States. By limiting and denying undocumented Hispanic/Latino youth, access to higher education, we are stripping these individuals of their potential. We are also robbing the United States of educated and productive citizens. If we want to benefit from students like Juanes, we need to improve educational access and break down the barriers that maintain "a dead-end future". Essentially, without a broader legalization system in place, and fairer educational policies, many undocumented immigrants will be neglected, and the United States as a whole will suffer. 


\section{REFERENCES}

Abrego, Leisy Janet. 2006. '“I Can’t Go To College Because I Don’t Have Papers: Incorporation Patterns of Hispanic/Latino Undocumented Youth.” Hispanic/Latino Studies 4; 212-231.

Alba, Richard D., Douglas Massey, and Rubén G. Rumbaut. 1999. The Immigration Experience for Families and Children. Washington, DC: American Sociological Association.

Alba, Richard and Victor Nee. 2003. Remaking the American Mainstream: Assimilation and Contemporary Immigration. Cambridge: Harvard University Press.

Balderrama, Francisco E., and Raymond Rodríguez. 2006. Decade of Betrayal: Repatriation in the 1930's. Albuquerque: University of New Mexico Press

Bean, Frank D., Jeffrey S. Passel, and Barry Edmonston. 1990. Undocumented Migration to the United States: IRCA and the Experience of the 1980's. Washington D.C.: Urban Institute Press.

Bernstein, Maxine. 2013. "Back-to-back Killings in Gresham Worry Police about Increased Gang Violence." The Oregonian, October 24. Retrieved November 8, 2013(http://www.oregonlive.com/gresham/index.ssf/2013/10/back-toback_killings_in_gresh.html).

Brown, Susan K., and Frank D. Bean. 2006. "Assimilation Models, Old and New: Explaining a Long-Term Process.” Migration Policy Institute, October 1. 
Retrieved January 15, 2012

(http://www.migrationinformation.org/USfocus/display.cfm?ID=442).

Camarillo, Albert. 1979. Chicanos in a Changing Society. Cambridge, MA: Harvard University Press.

Chávez, Leo R. 1998. Shadowed Lives: Undocumented Immigrants in American Society. Fort Worth, TX: Harcourt Brace.

Gándara, Patricia. 2010. "Special Topic: The Hispanic/Latino Education Crisis." Educational Leadership 67(5); 24-30. Retrieved June 18, 2014 (http://www.ascd.org/publications/educationalleadership/feb10/vol67/num05/The-Hispanic/Latino-Education-Crisis.aspx).

Garret, Patrick. 2013. “Gang Enforcement.” Washington County Sheriff's Office. Retrieved November 8, 2013 (http://www.co.washington.or.us/Sheriff/FightingCrime/SpecialResponseTeams/g ang-enforcement.cfm).

Gonzales-Berry, Erlinda V., and Marcela Mendoza. 2010. Mexicanos in Oregon: Their Stories, Their Lives. Corvallis: Oregon State University Press.

Gonzales, Manuel G. 1999. Mexicanos: A History of Mexicans in the United States. Bloomington: University of Indiana Press.

Gonzales, Roberto. 2009. Young Lives on Hold: The College Dreams of Undocumented Students. Washington, D.C.: College Board Advocacy. Retrieved March 27, 2012 (http://professionals.collegeboard.com/profdownload/young-lives-on-holdcollege-board.pdf). 
Gonzales, Roberto. 2008. "Born in the Shadows: The Uncertain Futures of Unauthorized Mexican Migrants." PhD dissertation, Department of Sociology, University of California, Irvine.

Gonzalez, Gilbert G. and Raul A. Fernandez. 2003. A Century of Chicano History: Empire Nations and Migration. New York, NY: Routledge.

Gordon, Milton. 1964. Assimilation in American Life: The Role of Race, Religion, and National Origins. New York: Oxford University Press.

Hing, Bill Ong. 2004. Defining America through Immigration Policy. Philadelphia: Temple University Press.

Immigration Equality. 2012. Deferred Action for Childhood Arrivals (DACA). Retrieved September 13, 2012 (http://immigrationequality.org/issues/immigrationbasics/daca/).

Kao, Grace, and Marta Tienda. 1995. "Optimism and Achievement: The Educational Performance of Immigrant Youth.” Social Science Quarterly 76(1): 1-19. López, Gerald P. 1981. "Undocumented Mexican Migration: In Search of a Just Immigration Law." UCLA Law Review 28: 615, 657.

MALDEF. 2012. "Toolkit on Deferred Action for Childhood Arrivals." Retrieved November 5, 2014 (http://www.maldef.org/).

National Gang Intelligence Center. 2011. “2011: National Gang Threat AssessmentEmerging Trends.” Department of Justice. Washington, D.C.: Government Printing Office.

National Immigration Law Center. 2013. Basic Facts about In-State Tuition for 
Undocumented Immigrant Students. Los Angeles: National Immigration Law Center. Retrieved May 12, 2013(http://www.nilc.org/basic-facts-instate.html).

Ngai, Mae. 2004. Impossible Subjects: Illegal Aliens and the Making of Modern America. Princeton, NJ : Princeton University Press.

Office of Governor Janice K. Brewer. 2010. “Common Myths and Facts Regarding Senate Bill 1070. ” Retrieved January 12, 2013 (www.azgovernor.gov/documents/BorderSecurity/SB1070MythsandFacts.pdf).

Ogbu, John U. 1991. "Immigrant and Involuntary Minorities in Comparative Perspective." Pp. 3-33 in Minority Status and Schooling: A Comparative Study of Immigrant and Involuntary Minorities, edited by Margaret A. Gibson and John U. Ogbu. Ney York: Garland.

Olivas, Michael A. 2005. "The Story of Plyler v. Doe, The Education of Undocumented Children, and The Polity.” Pp.197-220 in Immigration Stories, edited by D. Martin and P. Schuck. New York: Foundation Press.

Passel, Jeffrey. 2003. "Further Demographic Information Relating to the DREAM Act." The Urban Institute. Retrieved September 17, 2012 (file:///C:/Users/Brittanie/Downloads/dream_demographics.pdf).

Perez, William, Roberta Espinoza, Karina Ramos, Heidi M. Coronado, and Richard Cortes. 2009. “Academic Resilience Among Undocumented Hispanic/Latino Students.” $\quad$ Hispanic Journal of Behavioral Sciences 20(10). Retrieved June 2, 2013 (http://www.williamperezphd.com/articles/perez-espinoza-ramos-coronadcortes- 2009.pdf). 
Piore, Michael. 1986. "The Shifting Grounds for Immigration." Annals of the American Academy of Political and Social Science 485:22-33.

Portes, Alejandro and Min Zhou. 1993. "The New Second Generation: Segmented Assimilation and Its Variants.” Annals of the American Academy of Political and Social Science 530: 74-96.

Portes, Alejandro and Rubén G. Rumbaut. 2001. Legacies: The Story of the Immigrant Second Generation. Berkeley and Los Angeles: University of California Press.

Ranchod Law Group Attorneys. 2014. "Pros and Cons of Deferred Action for Childhood Arrivals- Dreamer Work Permit. ” Ranchod Law Group. Retrieved April 12, 2014 (http://www.ranchodlaw.com/blog/dreamer-work-permit/pros-and-cons-ofdeferred-action-for-childhood-arrivals-dreamer-work-permit/).

Roberts, Brittanie. 2010. "Broken Dreams: Undocumented Hispanic/Latino Immigrant Youth Student Community of Oregon's Portland Metro Area." Paper presented at the Portland State University Youth Subcultures class, May 10, Portland, OR.

Rumbaut, Rubén G. and Kenji Ima. 1988. The Adaptation of Southwest Asian Refugee Youth: A Comparative Study. Washington, DC: U.S. Office of Refugee Resettlement.

Russell, Alene. 2011. "State Policies Regarding Undocumented College Students: A Narrative of Unresolved Issues, Ongoing Debate, and Missed Opportunities." American Association of State Colleges and Universities. Retrieved April 12, 2014 
(http://www.nacacnet.org/research/KnowledgeCenter/Documents/Undocumented CollegeStudents.pdf).

Schmidt Camacho, Alicia R. 2008. Migrant Imaginaries: Hispanic/Latino Cultural Politics in the U.S.-Mexico Borderlands. New York: New York University Press. Seif, Hinda. 2004. “'Wise Up!: Undocumented Hispanic/Latino Youth, MexicanAmerican Legislators, and the Struggle for Higher Education Access." Hispanic/Latino Studies 2(2): 210-230.

Sparrow, Paul, ed. 2009. Handbook of International Human Resource Management: Integrating People, Process, and Context. United Kingdom: John Wiley \& Sons. Stepick, Alex and Carol Dutton Stepick. 2012. "The Complexities and Confusions of Segmented Assimilation.” Pp. 7-20 in Theorising Integration and Assimilation, edited by Jens Schneider and Maurice Crul. New York: Routledge.

Supiano, Beckie. 2008. "Views on Immigrants Cost 3 California Community-College Trustees Their Posts." The Chronicle of Higher Education: Money and Management 54(23). Retrieved on April 12, 2014 (http://www.csun.edu/pubrels/clips/Feb08/02-11-08B1.pdf).

U.S. Census Bureau. 2013. "State and County Quick Facts." Washington, D.C.: Government Printing Office.

U.S. Department of Homeland Security. 2013. "Deferred Action for Childhood Arrivals." Retrieved June 13, 2014 (http://www.dhs.gov/deferred-action-childhood-arrivals). U.S. Department of Homeland Security. 2013. "U.S. Citizenship and Immigration Services: Immigration Reform and Control Act of 1986 (IRCA).” Retrieved 
November 6, 2013 (www.uscis.gov/tools/glossary/immigration-reform-and control-act-1986-irca).

Valdés, Guadalupe. 1996. Con Respeto: Bridging the Distances between Culturally Diverse Families and Schools. New York: Teachers College Press.

Valenzuela, Angela. 1999. Subtractive Schooling: U.S.-Mexican Youth and the Politics of Caring. New York: State University of New York Press.

Vargas, Lucila and Bruce dePyssler. 1998. "Using Media Literacy to Explore Stereotypes of Mexican Immigrants.” Retrieved May 25, 2014 (http://worldroom.tamu.edu/Presentations/Making\%20History\%20Come\%20Aliv e/Making\%20History\%20Come\%20Alive\%20CD/Articles/Media\%20Literacy/Us ing\%20Media\%20Literacy\%20to\%20Explore\%20Stereotypes.doc).

Vasquez, Jessica M. 2011. “The Bumpy Road of Assimilation: Gender, Phenotype, and Historical Era." Sociological Spectrum 31(6): 718-748. 


\section{APPENDIX}

\section{Informed Consent Cover Letter}

The Impact of Documentation Status on the Educational Attainment Experiences of Undocumented Hispanic/Latino Students

My name is Brittanie Roberts and I am a graduate student at Portland State University. I am conducting research for my master's thesis for the college of liberal arts and sciences. You have received this cover letter because you have been determined to be eligible for this research, and I would like to invite you to participate. Your input and cooperation will contribute greatly to this research.

My research focuses on undocumented Hispanic/Latino students' perceptions of legal status barriers and the impact these barriers have on their educational attainment experiences. How undocumented Hispanic/Latino youth understand the choices or opportunities available to them if they are unable to access post-secondary education in the U.S. is a significant part of the "educational attainment experience". The motivation for this thesis is my desire to identify and address factors which make college difficult to attend or impossible altogether, and the consequences of these factors. I want to know possible long term consequences of inaccessible education for these students from their perspective, and how they feel it will affect their personal futures, their goals, and their larger communities.

"Educational attainment experiences" is not only experience in accessing education, but experience in being denied education as well. I also want to know what systems or relationships these students feel are beneficial, and what they perceive to be detrimental to their educational attainment success. This research involves me interviewing undocumented Hispanic/Latino students between the ages of 18 and 25, who immigrated to the United States before their $16^{\text {th }}$ birthday. All interviews will be recorded, transcribed and relevant information will be used as part of the final thesis.

I want to assure you that all information discussed in these interviews will be kept confidential. I will keep my notes on this conversation in a locked file drawer, along with the recording. When we write anything to be published, I will not include any details that could identify you, such as your name, the name of your employer or any unusual family circumstances or personal characteristics. Your participation in this project is completely voluntary, and will not affect your relationship with anyone else. You may stop this conversation at any point, if you wish to do so.

If you have concerns about your participation in this study, you may contact the Portland State University Human Subjects Research Review Committee, Office of Research and Sponsored Projects. They are located at 600 Unitus Building, Portland OR, and can be reached by phone at (503) 725-4288, or toll-free, 1-877-480-4400.

If you have questions regarding the interviews or the study itself, feel free to contact me at (503) 704-9876, or my faculty advisor, Margaret Everett, at (503) 725-5258. Please keep this letter so that you have our contact information available.

Thank you for your interest, and I look forward to working with you on this research.

Brittanie Roberts 